\title{
DESIGN OF STANDARDS OF INDUCTANCE, AND THE PROPOSED USE OF MODEL REACTORS IN THE DESIGN OF AIR-CORE AND IRON-CORE REACTORS
}

\author{
By H. B. Brooks
}

ABSTRACT

After a brief discussion of the various uses of reactors and the general characteristics of formulas for the self-inductance of coils, a number of useful general relations concerning the self and mutual inductance of geometrically similar coils are given with illustrative derivations of some of these relations. Three applications of some of these relations are developed in the remainder of the paper. The first is a simple and straightforward procedure for the design of air-core coils to serve as standards of self-inductance and is believed to be the first such design procedure for this specific purpose to be published. The second application proposes that the self and mutual inductance of the large current-limiting reactors used in power systems may be advantageously predetermined, or their computed values checked, by laboratory tests made on small-scale models. The third application proposes to use models for the checking or predetermination of the properties of iron-core air-gap reactors. In developing the theory of this application it is shown that such reactors have their desirable optimum performancethat is, minimum power factor-when the relative length of the air gap is such as to make the copper loss equal to the core loss for the desired maximum magnetic flux density in the core.

\section{CONTENTS}

I. Introduction

1. Definitions .

2. Some of the uses of reactors

(a) As laboratory standards of inductance

(b) In electrical instruments....................

(c) For compounding synchronous converters........

(d) For paralleling transformers of unlike inherent reactance.

(e) For limiting short-circuit currents.......

3. Objects of this paper

Page

290

290

291

291

291

291

291

291

292

4. The criterion, time constant.

5. General characteristics of formulas for the self-inductance of a coil

6. Optimum form of coil

7. Improved form of Maxwell-Rosa formula for the self-inductance of a circular coil of rectangular cross section

8. Convenient condensed formulas for the self-inductance of coils of optimum form

II. General relations concerning self and mutual inductance of geometrically similar coils

III. Design of standards of self-inductance

1. Range of frequencies covered.

2. Requirements to be met by standards of self-inductance for laboratory use

3. Procedure for the design of self-inductance standards....

(a) General considerations affecting the design

(b) Desired value of time constant is the starting point.-

(c) Design of a coil of 1 millihenry inductance.......

(d) Design of a coil of any value of inductance.......-

(e) Deviation of actual wire from tabular data

(f) Checking the design values; taking care of varia- 
III. Design of standards of self-inductance-Continued.

3. Procedure for the design of self-inductance standards-Con

(g) Time constant and weight of final coil

(h) Numerical example of design

(i) Design of a coil of given inductance to fill a given spool

(j) Design of a coil of given inductance of wire of given diameter

(k) Data for the plotting of the design curves

(l) Adjustment of the standard to its nominal

(m) Materials for the spool; binding posts

(n) Temperature coefficient of standards of inductance.

(o) Sets of inductance coils . ...

IV. Current-limiting reactors for power systems

1. Special requirements....

(a) Ability to withstand heating caused by heavy over-

(b) Ability to withstand destructive forces during short circuits

(c) High flash-over voltage 314

(d) Low skin-effect resistan

2. Design procedures in use resistance ratio _............... 314

3. Usefulness of models to designers in various felds

4. Suggested use of models in the design of fields reactors

(a) Useful relations

(b) Checking the self inductance 316

(c) Checking the skin-effect resistance ratio reactors--- 316 reactors

(d) Checking the mutual inductance between full-size reactors

(e) Checking the electrodynamic forces between full: size reactors

(f) Electrodynamic torque between 318

V. Iron-core air-gap reactors

1. Scope of this discussion

2. Reason for the use of an air gap

$\begin{array}{ll}\text { 3. Condition for the desirable minimum power factor } & 320 \\ 4 . & \end{array}$

4. Suggested use of model reactors as a check on present methods of design

5. Suggested use of model reactors as an independent basis of

(a) Uncertainty as to gap reluctance, 325

(b) Choice of form of core reluctance, stray flux, etc ---325

(b) Choice of form of core and location of gap..... 326

(c) Choice of core material and maximum flux density - 326

(d) Experiments to be made with the model $\ldots . . . .--\quad 326$

6. Condition for minimum power factor in each of a series of 327

VI. geometrically similar reactors .........

\section{INTRODUCTION}

\section{DEFINITIONS}

A reactance coil, or for brevity, a reactor, is a device used for the purpose of introducing inductive reactance in an electric circuit, and is usually designed to have a high time constant (ratio of inductance to resistance). This is because the useful property is the inductance, ${ }^{1}$

1 While the term "inductor" would have the advantage of not necessarily implying operaion nating current, it and the related word "induction" have been rather The term "reactor" has the disadvantages of involv" have been rather overworked in electrotechnics. ambiguous to the extent that reactance, strictly volving the idea of some definite frequency, and is also latter aspect is being taken areactance, strictly speaking, may ke either inductive or capacitive. This capacitive reactance as a "capacitor" some extent, by the growing tendency to speak of a device possessing denser," and in line with the useful term "resistor" " the ambiguity of the earlier and illogical term "con- 
and, therefore, the reactance at a specified frequency; and the associated resistance is ordinarily either useless or detrimental. One of the major problems in reactor design is therefore to keep the resistance at the lowest value possible with the expenditure of a given amount of material.

For convenience, reactors may be divided into two general classes, namely, air-core reactors and iron-core reactors. The expression "air-core" might be replaced by "ironless." It does not exclude the use of any material for the core or other supporting structure of the reactor which has a permeability of unity and is either a nonconductor or is so arranged that eddy currents will not be set up in it. The term "iron-core reactor" is self-defining.

\section{SOME OF THE USES OF REACTORS}

\section{(a) AS LABORATORY STANDARDS OF INDUCTANCE}

Reactance coils used for this purpose are of two general classes; first, those wound on precisely measured forms in such a way that the inductance can be computed from the dimensions; and second, coils wound in any convenient form and adjusted to definite values of inductance by reference to known standards. The former class will not be considered in this paper. In both classes the coil must be wound on supports of nonmagnetic insulating material.

(b) IN ELECTRICAL INSTRUMENTS

Iron-core reactors of small size are used in frequency meters and some other alternating-current instruments.

(c) FOR COMPOUNDING SYNCHRONOUS CONVERTERS

Larger iron-core reactors are used in the alternating-current circuit supplying a synchronous converter in order to secure compounding.

(d) FOR PARALLELING TRANSFORMERS OF UNLIKE INHERENT REACTANCE

Transformers of like ratio but of unlike characteristics as regards relative resistance and leakage reactance may operate satisfactorily in parallel on light loads but may divide heavier loads so disproportionately as to overload some of the transformers seriously. The addition of suitable amounts of external resistance and reactance to those transformers having relatively small values of these quantities will cause the load to be divided properly.

\section{(e) FOR LIMITING SHORT-CIRCUIT CURRENTS}

Probably the most conspicuous use of reactors at the present time is for the purpose of limiting the amount of current which can flow in the generators, busses, and feeders of electric-power systems. Without the protection afforded by current-limiting reactors or some equivalent device ${ }^{2}$ it would not be practicable to use generating units of the very large ratings now used because of the extremely destructive forces and heating effects which would be caused by short-circuit currents.

${ }^{2}$ Resistors of iron strips have been used experimentally in Germany for this purpose. They are dimen sioned to have only a small temperature rise with the working current, but to approach a red heat at maximum short-circuit current. The use of resistors in parallel with reactors has been investigated by Kierstead, Rorden, and Bewley; see Trans. Amr. Inst. Elec. Engrs., 49, pp. 1161-1178; 1930. 


\section{OBJECTS OF THIS PAPER}

The objects of this paper are to present a number of useful general relations concerning the self and mutual inductance of geometrically similar coils, and to illustrate their usefulness by making three applications of them. The first application relates to coils serving as standards of self-inductance for laboratory purposes. The advantages of the Maxwell-Shawcross-Wells optimum form of coil for this purpose are emphasized, and a convenient and rapid procedure for the design of such coils is given. The second proposed application is the use of small model coils for predetermining the dimensions and performance of large current-limiting reactors as used in power plants. In the third application the use of small-scale iron-core air-gap reactors is proposed for the predetermination of the dimensions and performance of large reactors of this type. In developing the theory of this last application it is brought out that iron-core air-gap reactors have the desirable minimum power factor when the length of the air gap is such that the copper loss equals the core loss.

\section{THE CRITERION, TIME CONSTANT}

The unavoidable resistance of a reactor is often a disadvantage, and the wire used in its construction should, therefore, be wound to form a coil having the greatest possible ratio of inductance to resistance; that is, the highest possible time constant. ${ }^{3}$ The circular form of coil is clearly to be preferred, and a rectangular cross section of winding is obviously the most convenient one. It has been found that from the standpoint of maximum time constant the most suitable rectangle is a square. The remaining question to be determined is the ratio of the side of the square cross section to the mean diameter of the winding.

\section{GENERAL CHARACTERISTICS OF FORMULAS FOR THE SELF- INDUCTANCE OF A COIL}

Examination of formulas for the calculation of the self-inductance of coils will show that the self-inductance is the product of three characteristic factors which may best be illustrated by an example. Referring to Figure $1(a)$, which shows a circular coil of rectangular cross section, Maxwell's approximate formula ${ }^{4}$ for the self-inductance is

where

$$
L=4 \pi a N^{2}\left(\log _{\mathrm{e}} \frac{8 a}{R}-2\right)
$$

$L=$ inductance in abhenries (millimicrohenries),

$a=$ mean radius in centimeters,

$N=$ total number of turns in the coil, and

$R=$ geometric mean distance ${ }^{5}$ of the cross section of the winding in centimeters.

\footnotetext{
When it is desired to have an inductance standard which will be nearly astatic as to local magnetic field, a sacrifice in time constant must be made. For example, the coil may be wound on a supporting torus of nonmagnetic material. A lesser degree of astaticism may be secured by the use of two coils in series, held in a fixed relation to each other, the coils having opposite instantaneous polarities as viewed from one side.

Maxwell, Electricity and Magnetism, 2, sec. 706.

- The geometric mean distance of a rectangle of sides $b$ and $c$ may be taken to be equal to $0.2236^{\circ}(b+c)$. While the coefficient actually varies between the limits 0.2231 and 0.2237 for rectangles of various relative proportions, the intermediate value 0.2236 gives results more than sufficiently accurate for engineering purposes. See B. S. Bull. 8, p. 168, 1912; Sci. Paper No. 169.
} 
The quantity in parentheses is the difference of two abstract numbers, and is a constant for all coils of the given form having the same relative values of $a, b$, and $c$. The three characteristic factors in the above expression for $L$ are the linear dimension $a$, the square of the number of turns, and the numerical coefficient whose value depends upon the relative proportions of the coil.

\section{OPTIMUM FORM OF COIL}

There are an infinite number of possible forms of circular coil of rectangular cross section which may be made from a given length of wire. One extreme is formed by winding the whole length to form a single very large circular turn. This gives the greatest possible value of $a$, but because the inductance varies as the square of the number of turns the resulting inductance is far below the maximum value possible. The other extreme is the case of a coil in which the

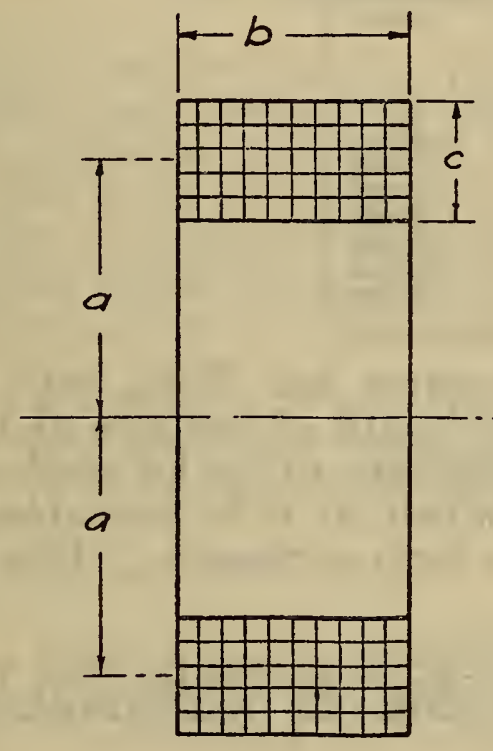

(a)

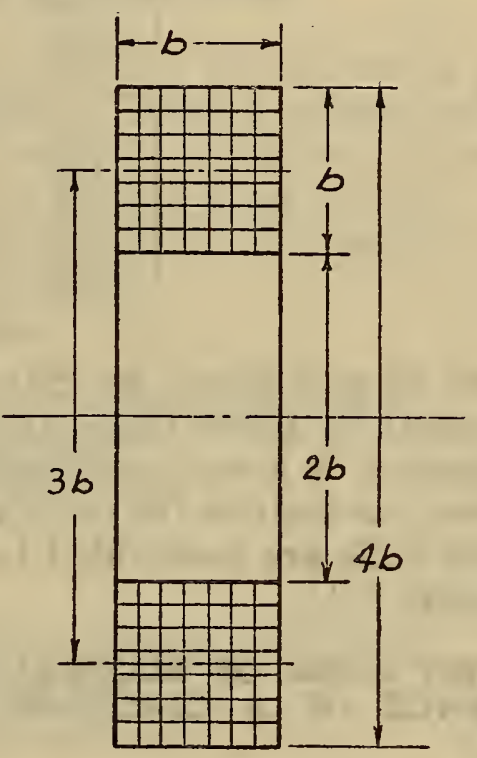

(b)

Figdre 1.-Cross-sectional diagrams of circular coils of rectangular cross section

(a), general form, without restriction as to relations between the values of $a, b$, and $c ;(b)$ optimum form for maximum time constant. Note the simple and easily remembered dimensional relations in the latter, namely, that the side of the square section, the inner diameter, mean diameter, and outside diameter of the coil are as $1: 2: 3: 4$.

radius $a$ of the mean turn is equal to one-half the side of the square cross section; that is, there is no hole through the center of the coil. This also gives a value of inductance which is less than that obtainable by an intermediate form.

Maxwell investigated the question of the most advantageous form ${ }^{6}$ of coil, but apparently did not carry enough terms of the formula he used to locate the maximum point as well as has been done later. He gave as the optimum form, for a coil of square cross section $(b=c$ in fig. $1(a))$, one in which the mean diameter, $2 a$, equals 3.7

- Maxwell, Electricity and Magnetism, 3d ed., 2, pp. 345-346.

$64825-31-6$ 
times the side $b$. It has since been found ${ }^{7}$ that the relation $2 a=3 b$, in other words, mean diameter equal to three times the side of the square cross section, gives a value of $L / R$ slightly greater ( 0.5 per cent) than is given by Maxwell's proportions.

Although the inductance theoretically has its maximum value when the ratio of the mean diameter to the side of the square cross section is 2.95 , the curve is so flat near the maximum that the use of the more convenient value 3 is fully warranted, as will appear from the following table, for which the author is indebted to Dr. Frederick W. Grover:

TABLE 1.-Inductance of a coil made of a given length of wire as a function of its form

\begin{tabular}{|c|c|}
\hline $\begin{array}{c}\text { Ratio of } \\
\text { mean } \\
\text { diameter } \\
\text { to side of } \\
\text { square } \\
\text { cross } \\
\text { section }\end{array}$ & $\begin{array}{c}\text { Inductance } \\
\text { in terms of } \\
\text { maximum } \\
\text { value }\end{array}$ \\
\hline 2.80 & 0.999606 \\
2.90 & .999971 \\
2.94 & .999994 \\
2.95 & 1.000000 \\
2.96 & .999994 \\
3.00 & .999953 \\
3.10 & .999594 \\
\hline
\end{tabular}

The form of coil given by Shawcross and Wells, with the mean diameter equal to three times the length of one side of the square winding channel, is a very convenient one to use for single standards of inductance, as well as for coils which are to be assembled in a box as resistance coils are assembled to form a rheostat. It is shown to scale in Figure 1(b).

7. IMPROVED FORM OF MAXWELL-ROSA FORMULA FOR THE SELFINDUCTANCE OF A CIRCULAR COIL OF RECTANGULAR CROSS SECTION

Maxwell's approximate formula, equation (1), gives for the optimum form of coil a value of inductance 5 per cent higher than that given by Rosa's more accurate modification ${ }^{8}$ of Maxwell's formula. Since this modified formula, as printed in Scientific Paper No. 169, is in an ambiguous form and involves the use of natural logarithms, and since common (base 10) logarithms are much more convenient to use, the following equivalent formula is given. In it the symbols $a, b$, and $c$ have the meanings assigned to them in Figure $1(a)$ and $N$ is the number of turns in the coil. It should be noted that this formula is general as to the relative values of $a, b$, and $c$; much simpler formulas will be derived from it for coils of the optimum form.

$$
\begin{aligned}
L=4 \pi a N^{2}\{ & {\left[2.303 \log _{10}\left(35.78 \frac{a}{b+c}\right)\right]\left[1+0.0094\left(\frac{b+c}{a}\right)\right] } \\
& \left.-\left[2+0.0031\left(\frac{b+c}{a}\right)^{2}\right]\right\}
\end{aligned}
$$

'Shawcross and Wells, Electrician, 75, p. 64; 1915. These writers used a formula more accurate than the approximate one used by Maxwell. J. Hak, Elektrotechnik und Maschinenbau, 46, pp. 249-250; 1928, arrives at practically the same result, namely, that the mean diameter should be 2.95 times the side of the square cross section.

${ }_{8}$ Rosa and Grover, B. S. Bull., 8, p. 136, equation (86); 1916; Sci. Paper No. 169. 
If the linear dimension $a$ in the quantity $4 \pi a N^{2}$ is in centimeters, this formula gives the inductance in abhenries (millimicrohenries). The quantity $a /(b+c)$ and its reciprocal are abstract numbers which depend upon the form of the coil, but not on its size, and do not change when $a, b$, and $c$ are expressed in other units. Consequently, for any given form of coil, the entire expression following $N^{2}$ is a numerical constant.

While the above formula of Rosa is not rigorously exact, it is sufficiently so for engineering purposes. Dr. Frederick W. Grover has kindly computed the inductance of a coil, of the optimum form about to be described, by the accurate formula of Lyle and has found that the above formula (2) gives a result 1 per cent lower than that given by Lyle's formula.

\section{CONVENIENT CONDENSED FORMULAS FOR THE SELF-INDUCTANCE OF COILS OF OPTIMUM FORM}

From the preceding formula, equation (2), the following convenient formulas have been derived for circular coils of square cross section having the optimum proportions, namely, the mean diameter (2 a) equal to three times the side of the square cross section. For convenience they are given in two groups, with the dimension $a$ expressed in centimeters and in inches, respectively.

Radius $a$ measured in centimeters:

$$
\begin{aligned}
L & =16.83 a \mathrm{~N}^{2} \text { abhenries (millimicrohenries) } \\
& =.01683 \mathrm{a} \mathrm{N}^{2} \text { microhenries } \\
& =.00001683 a \mathrm{~N}^{2} \text { millihenries }
\end{aligned}
$$

Radius $a$ measured in inches:

$$
\begin{aligned}
L & =42.74 a \mathrm{~N}^{2} \text { abhenries (millimicrohenries) } \\
& =.04274 a \mathrm{~N}^{2} \text { microhenries } \\
& =.00004274 a N^{2} \text { millihenries }
\end{aligned}
$$

It is obvious that the 4-figure accuracy implied by the numerical coefficients in the preceding six formulas can not ordinarily be realized in $a$ or $N^{2}$. The coefficients may be abbreviated by the user as circumstances may justify. These formulas presuppose uniform distribution of the current over the square cross section of the coil. The design curves of Figures 3 and 4 are for the case of round wires with insulation of negligible thickness. Although the inductance in the latter case is slightly larger than would be given by the above uniform-distribution formulas, the correction term for coils of 100 turns or more is negligible for the present purpose. As a matter of theoretical interest, the magnitude of the correction for any given number of turns in the coil may be readily found by comparing the result given by formula (3) with that obtained from the approximate but sufficiently accurate expression

$$
L=16.83 a N^{2}\left(1+\frac{0.116}{N}\right) \text { abhenries }
$$

which is formula (3) with a correction factor added. 


\section{GENERAL RELATIONS CONCERNING SELF AND MUTUAL INDUCTANCE OF GEOMETRICALLY SIMILAR COILS}

The following general relations apply to geometrically similar coils of any form whatever, located in media of equal and constant permeability. The coils under comparison are assumed to be closely wound of wires of the same resistivity and the same density, and (where so specified) of the same space factor. While the relations are assumed primarily to apply to closely wound coils, for which the diameter of the wire (over the insulation) determines the number of turns per layer and the number of layers, they hold also (with obvious changes in wording) for coils with air spaces between adjacent turns and between adjacent layers, if the specification of geometrical similarity includes the cross sections of the conductors and of the air spaces about the conductors.

(a) For coils of the same absolute size the self-inductance is proportional to the square of the number of turns; conversely, the number of turns is proportional to the square root of the self-inductance.

(b) For coils of the same absolute size the self-inductance is inversely proportional to the fourth power of the diameter of the wire over the insulation; conversely, the diameter of the wire over the insulation is inversely proportional to the fourth root of the inductance.

(c) For coils of a given self-inductance the diameter of the wire over the insulation is proportional to the five-fourths power of a given coil dimension; conversely, each coil dimension is proportional to the fourfifths power of the diameter of the wire over the insulation.

(d) For coils of a given self-inductance the number of turns is inversely proportional to the square root of a given coil dimension.

(e) For coils of a given self-inductance wound with wires having the same space factor, the diameter of the wire over the insulation is proportional to the five-eights power of the time constant.

$(f)$ For coils of a given self-inductance, wound with wires having the same space factor, each coil dimension is proportional to the square root of the time constant.

$(g)$ For coils having the same number of turns the self-inductance is proportional to the first power of a given coil dimension.

(h) For coils wound with wire of the same diameter over the insulation, the self-inductance is proportional to the fifth power of a given coil dimension; conversely, ench coil dimension is proportional to the one-fifth power of the self-inductance.

(i) For coils wound with wires having the same space factor the timeconstant $L / R$ is proportional to the square of a given coil dimension.

(j) For coils wound with wires having the same space factor the mass of conducting material in the coil is proportional to the threehalves power of the time constant, and the mass of conducting material per unit of time constant is proportional to the first power of a given coil dimension. Large coils thus require more conducting material per unit of time constant than small ones.

(k) For coils of a given size, wound with wires having the same space factor, the time constant, the mass of conducting material in the coil, and the mass of conducting material per unit of time constant are independent of the size of the wire and, therefore, of the value of the inductance. 
The following relations apply to the mutual inductance of geometrically similar pairs of coils in geometrically similar relative positions, under the same general conditions specified for the cases of self-inductance:

(l) For pairs of coils of the same absolute size the mutual inductance is proportional to the product, primary turns times secondary turns, for the respective pairs of coils. Note that the value of the mutual inductance of any pair of coils does not depend on which one is taken as the primary.

$(m)$ For pairs of coils of the same absolute size having a constant ratio of diameter (over insulation) of wire in the primary coil to diameter of wire in the secondary coil, the mutual inductance varies inversely as the fourth power of the diameter of the wires in corresponding coils of the two pairs; conversely, the diameter of the wires in corresponding coils is inversely proportional to the fourth root of the mutual inductance.

$(n)$ For pairs of coils having the same number of turns in corresponding coils, the mutual inductance is proportional to the first power of a linear coil dimension.

Relations $(l),(m)$, and $(n)$ are merely extensions of relations $(a)$, $(b)$, and $(g)$ for the self-inductance of geometrically similar coils. They indicate the manner in which relation $(c)$ and others for the case of self-inductance may be restated for the case of mutual inductance. With suitable additional limitations made necessary by the magnetic properties of iron and similar magnetic materials, general relations may be stated for the self-inductance of iron-core air-gap reactors. Such of these relations as are necessary for the purpose are given later in this paper (p. 322) in discussing the proposed use of small-scale iron-core reactors as a basis for designing full-size reactors. Certain general relations concerning mutual translational forces and mutual torques of geometrically similar pairs of coils are developed in a later section of this paper (p. 318) on current-limiting reactors for power systems.

An obvious practical limitation, which is ignored in stating some of the above relations, is that, in general, for an arbitrarily chosen diameter of wire over the insulation, there will not be an exactly integral number of turns per layer or of layers in the coil. This matter is readily cared for in the design and construction of actual coils. (See p. 305.)

It is obvious that the relations above given do not exhaust the list of possible relations of this kind, but it is believed that they include all of the more important ones of practical applicability.

The process of reasoning by which the preceding general theorems are demonstrated may be illustrated by giving the derivation of relations $(g),(i)$, and $(j)$. Assume two geometrically similar 1-turn coils, $a$ and $b$, made of identical conducting material, each dimension of $b$ being $n$ times the corresponding dimension of $a$. Let $l_{a}, l_{b}, s_{a}$, $s_{b}$ denote the lengths and cross sections of the two conductors, and $R_{a}, R_{b}, L_{a}, L_{b}$ their resistances and inductances. Then we have

from which

$$
\frac{R_{b}}{\bar{R}_{a}}=\frac{\rho n l_{a} / n^{2} s_{a}}{\rho l_{a} / s_{a}}
$$

$$
R_{b}=R_{a} / n
$$


The magnetic circuit of coil $b$ has everywhere a cross section $n^{2}$ times as great as the corresponding cross section of $a$, and the length of each flux path in $b$ is $n$ times as great as that of the corresponding flux path in $a$; hence the reluctance of the magnetic circuit of $b$ is $1 / n$ times that of $a$. Unit current flowing in $b$ will thus set up $n$ times as many linkages as will be caused by unit current in $a$, which is equivalent to the statement that

$$
L_{b}=n L_{a}
$$

If instead of one turn the conducting material now forms $m$ turns in each coil, both $L_{a}$ and $L_{b}$ are multiplied by $m^{2}$, but $L_{b}$ is still $n$ times as great as $L_{a}$. This proves relation $(g)$.

Coil $b$ has $n$ times the inductance of coil $a$ and $1 / n$ times the resistance of coil $a$; hence the ratio of their time constants is

from which

$$
\frac{\tau_{b}}{\tau_{a}}=\frac{n L_{a} /\left(R_{a} / n\right)}{L_{a} / R_{a}}
$$

which proves relation $(i)$.

$$
\tau_{b}=n^{2} \tau_{a}
$$

The mass of conducting material in coil $b$ is $n^{3}$ times that in coil $a$, and the time constant of $b$ is $n^{2}$ times that of $a$; hence the mass of conducting material is proportional to the 3 -halves power of the time constant, and the mass of conducting material per unit of time constant is proportional to the first power of a given coil dimension. These results prove relations $(j)$.

While some of the general relations given above are so well known as to be almost axiomatic, others have not been given previously, to the writer's knowledge. Some of these relations have formed the basis on which a simple and sufficiently accurate procedure has been devised for the design of coils to serve as standards of self-inductance. This is believed to be the first straightforward design procedure for this particular purpose, and will now be described.

\section{DESIGN OF STANDARDS OF SELF-INDUCTANCE}

\section{RANGE OF FREQUENCIES COVERED}

The form of coil and the design procedure about to be described are intended to be used for frequencies of not more than say several thousand cycles per second. The reason for this limitation is that in addition to inductance and the usually undesirable resistance, inductance coils have capacitance between each element of conductor surface and every other element. The effect of this distributed capacitance is to make the effective inductance of the coil vary with the frequency. For the closely wound coils which are discussed in this section of this paper, capacitance effects are small for frequencies up to a few hundred cycles per second, but may amount to several per cent for frequencies of say 1,000 to 3,000 cycles per second. The magnitude of the effect is greater for inductance standards of the higher values. For example, the inductance of a 1-henry standard changed 3 parts in 1,000 when the frequency was changed from 100 to 1,000 cycles, and 3 per cent for a change from 100 to 3,000 cycles. For a 100-millihenry standard the corresponding changes were about one-tenth of these figures. 
These observed results are in good agreement with the approximate formula ${ }^{9}$

$$
L^{\prime}=L\left(1+\omega^{2} C L\right)
$$

in which $L^{\prime}$ is the measured inductance, $L$ the true inductance, $C$ the capacitance which, in parallel with the coil, would produce the same effect as the actual distributed capacitance, and $\omega$ equals $2 \pi$ times the frequency.

\section{REQUIREMENTS TO BE MET BY STANDARDS OF SELF-INDUCTANCE FOR LABORATORY USE}

Standards of self-inductance for laboratory purposes are ordinarily used with currents small enough not to cause appreciable heating. The principal limiting performance consideration is usually the time constant $L / R$. The larger the coil, other things being equal, the larger the time constant; that is, the smaller the undesirable resistance of the coil for a given value of inductance. The most suitable material for the wire is copper. The ideal coil would be wound with square (or rectangular) wire with insulation of zero thickness; such a coil would have a "space factor" of unity. A coil of round wire with insulation of zero thickness, closely wound so that the turns do not imbed, ${ }^{10}$ will have a space factor of 0.7854 . The nearest approach to the ideal zero-thickness insulation is the so-called enamel insulation, for which the thickness of the insulation ranges from about 1 per cent of the diameter of the bare wire, in the largest sizes, to about 5 per cent in fine sizes.

\section{PROCEDURE FOR THE DESIGN OF SELF-INDUCTANCE STANDARDS}

(a) GENERAL CONSIDERATIONS AFFECTING THE DESIGN

The design procedure about to be described could have been worked out to apply to coils of any specified form. As given, however, it makes use of formulas (3) to (8), and consequently is limited to circular coils of square cross section having the mean diameter equal to three times the side of the square cross section, as shown in Figure $1(b)$.

Assuming that the currents to be carried are small, the limiting considerations in projecting the design of an inductance standard or a set of standards will usually be the size, weight, and cost of the coil. The desirable operating quality, which even with the optimum form of coil is to be had only at the expense of size, weight, and cost, is a sufficiently high value of time constant. A convenient unit for this quantity, for the present purpose, is the millisecond. ${ }^{11}$ Small coils for use in making up a set of four or more standards of inductance will have a time constant of about 1 millisecond. Larger coils for use as single standards have time constants of 2 to 10 milliseconds. A

\footnotetext{
9 Rosa and Grover, B. S. Bull. 3, p. 303; 1907.

10 Solenoids, by Underhill, $2 d$ ed., p. 232 .

11 If a coil having a time constant of 1 millisecond is connected to a noninductive d. c. source of negligible resistance and inductance (a storage cell is a good approximation to this) the current rises along a logarithmic curve and at the end of 0.001 second reaches a value of $(1-1 / \mathrm{e})$ times its final steady value; that is, 0.632 times this final value.

The concept of time constant is not limited, however, to that above outlined for the case of growth of current in a coil suddenly connected to a direct-current source. In the case of a coil connected to an a. c. source of frequency $f$, the time constant may be regarded as the quotient of $\tan \theta$ (equals $L \omega / R$ ) by $\omega$, where $\omega$ is equal to $2 \pi f$. The time constant is thus a constant of the coil which is independent of frequency (leaving out of consideration the change in skin efiect with frequency) but which, with the frequency, determines the angle of lag. If the time constant $r=L / R$ of the coil is large in comparison with the period $T$ of the a. c. source, the reactance of the coil predominates; if $\tau$ is small compared with $T$, its resistance predominates.
} 
number of such coils are shown in Figure 2, to serve as illustrations of usual practice. Particulars concerning these coils are given in Table 2.

TABLE 2.-Data on standards of inductance

\begin{tabular}{|c|c|c|c|c|c|}
\hline Symbol & Inductance & Resistance & $\begin{array}{c}\text { Time-con- } \\
\text { stant }\end{array}$ & \multicolumn{2}{|c|}{ Weight } \\
\hline $\begin{array}{l}A^{A}{ }^{1}- \\
{ }^{2}-2 \\
C^{2}{ }^{2}-\end{array}$ & $\begin{array}{r}\text { Millihenries } \\
1 \\
1 \\
10 \\
100\end{array}$ & $\begin{array}{c}\text { Ohms } \\
0.75 \\
.39 \\
2.88 \\
24.2\end{array}$ & \begin{tabular}{|r|} 
Milliseconds \\
1.3 \\
2.6 \\
3.5 \\
4.1
\end{tabular} & $\begin{array}{r}\text { Kilograms } \\
0.124 \\
.69 \\
.88 \\
1.17\end{array}$ & $\begin{array}{r}\text { Pounds } \\
0.27 \\
1.52 \\
1.94 \\
2.58\end{array}$ \\
\hline $\begin{array}{l}E^{3} \\
F{ }^{3} \\
G{ }^{3} \\
H^{5}\end{array}$ & $\begin{array}{r}1,000 \\
100 \\
100 \\
1,000\end{array}$ & $\begin{array}{l}97.0 \\
10.1 \\
20.8 \\
96.0\end{array}$ & $\begin{array}{r}10.3 \\
9.9 \\
4.8 \\
10.4\end{array}$ & $\begin{array}{l}4.03 \\
\text { 2. } 65 \\
3.46 \\
4.73\end{array}$ & $\begin{array}{r}8.8 \\
5.8 \\
7.6 \\
10.4\end{array}$ \\
\hline
\end{tabular}

1 Wound on maple spool; one of the set of coils. (Fig. 8.)

2 Wound on white marble spools; of German manufacture. Spools B and C are of identical dimensions. The low value of time constant of $B$ results from an unsuitable choice of diameter of wire, in consequence of which the desired inductance of 1 millihenry is had when only three-fourths of the winding space is filled. Note the difference in weight of the 2 coils

3 Wound on mahogany spool; of French manufacture. The binding posts might well be reduced in size, placed closer together and farther from the axis of the coil.

4 Wound on impregnated marble spool; of German manufacture. The binding posts are of the smallest practicable dimensions. For its size, weight, and value of inductance, this coil has a low value of time constant because the winding is made of "litzendraht" with the intention of making the coil suitable for higher frequencies. The space factor of litzendraht is low.

3 Wound on serpentine spool; of German manufacture. Binding posts have the good features of being small, close together, and in the best possible location as regards the magnetic field.

\section{(b) DESIRED VALUE OF TIME CONSTANT IS THE STARTING POINT}

The larger the time constant, the larger, heavier, and more expensive will be the inductance standard. The representative coils shown in Figure 2, with the accompanying data in Table 2, will assist in the choice of a feasible preliminary value of time constant. To simplify the work, the curves of Figures 3 and 4 have been prepared, the former in metric units, the latter in English units of coil dimensions and wire dianeters. The auxiliary curve (fig. 5) applies to either case, and is merely a method of graphically finding the reciprocal of the fourth power of any number within a given range. Because of the various kinds of wire insulations, for each of which the space factor of a winding varies, in general, with the diameter of the wire, the curves of Figures 3 and 4 are prepared for an ideal case of round wires having insulation of zero thickness, wound closely without embedding of the layers. The first values taken from these curves consequently need subsequent modification to care for the lower space factors of actual insulated wires. The manner of doing this will be indicated. Two design procedures are described, one for use when the desired value of inductance is 1 millihenry, the other for any other value $L$ millihenries. The former case is simpler, and will be taken up first.

\section{(c) DESIGN OF A COIL OF 1 MILLIHENRY INDUCTANCE}

The curves of Figure 3 or Figure 4 are entered with the desired value of time constant, and preliminary values $b^{\prime}, d^{\prime}$, and $w^{\prime}$ of the length of the side of the square cross section of the coil, the diameter of the wire, and the weight of copper are found. These values apply to the ideal case of insulation of zero thickness.

Reference to a table of data on wires having the desired kind of insulation will usually show that the preliminary value $d^{\prime}$ lies 


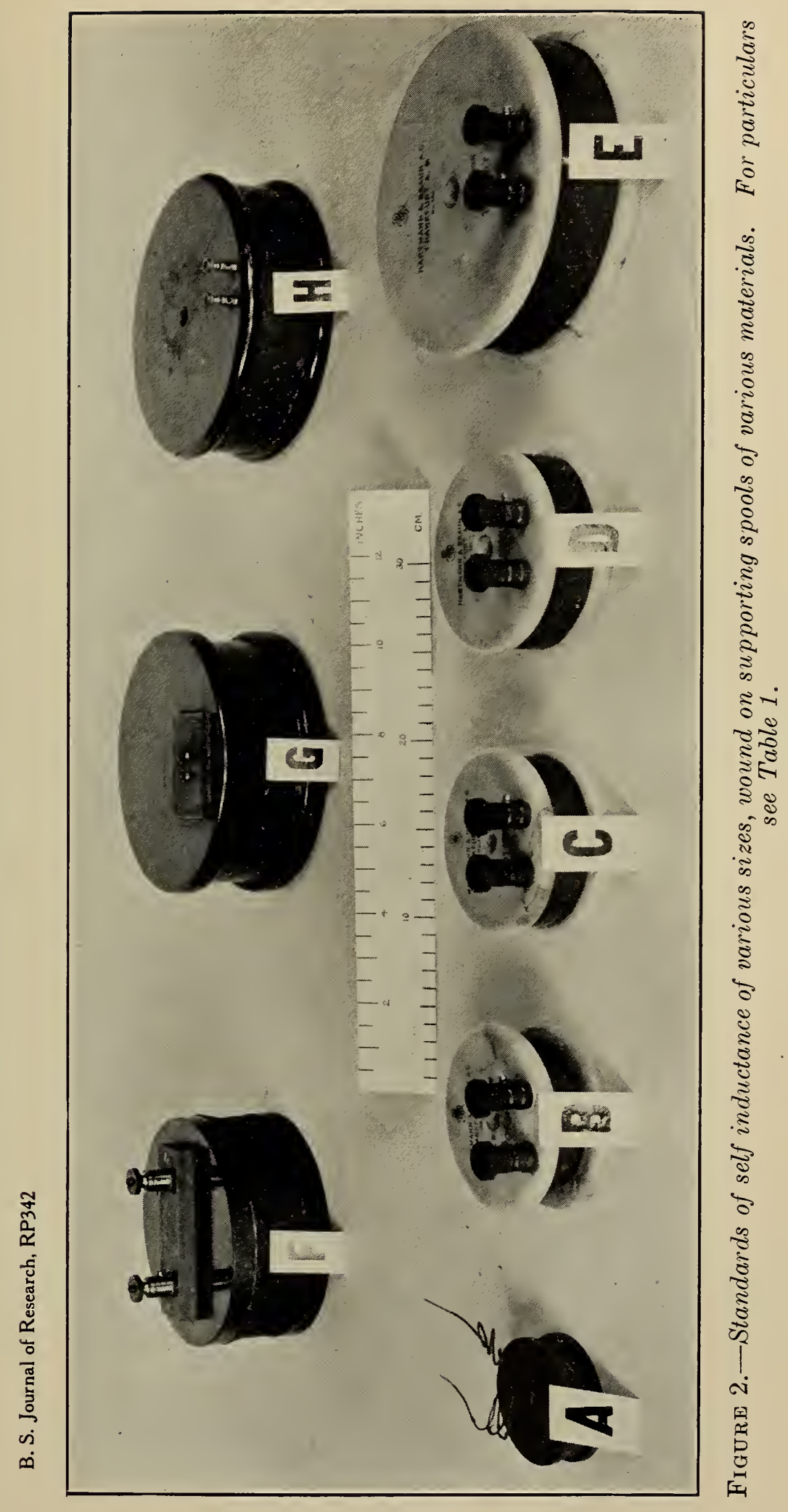




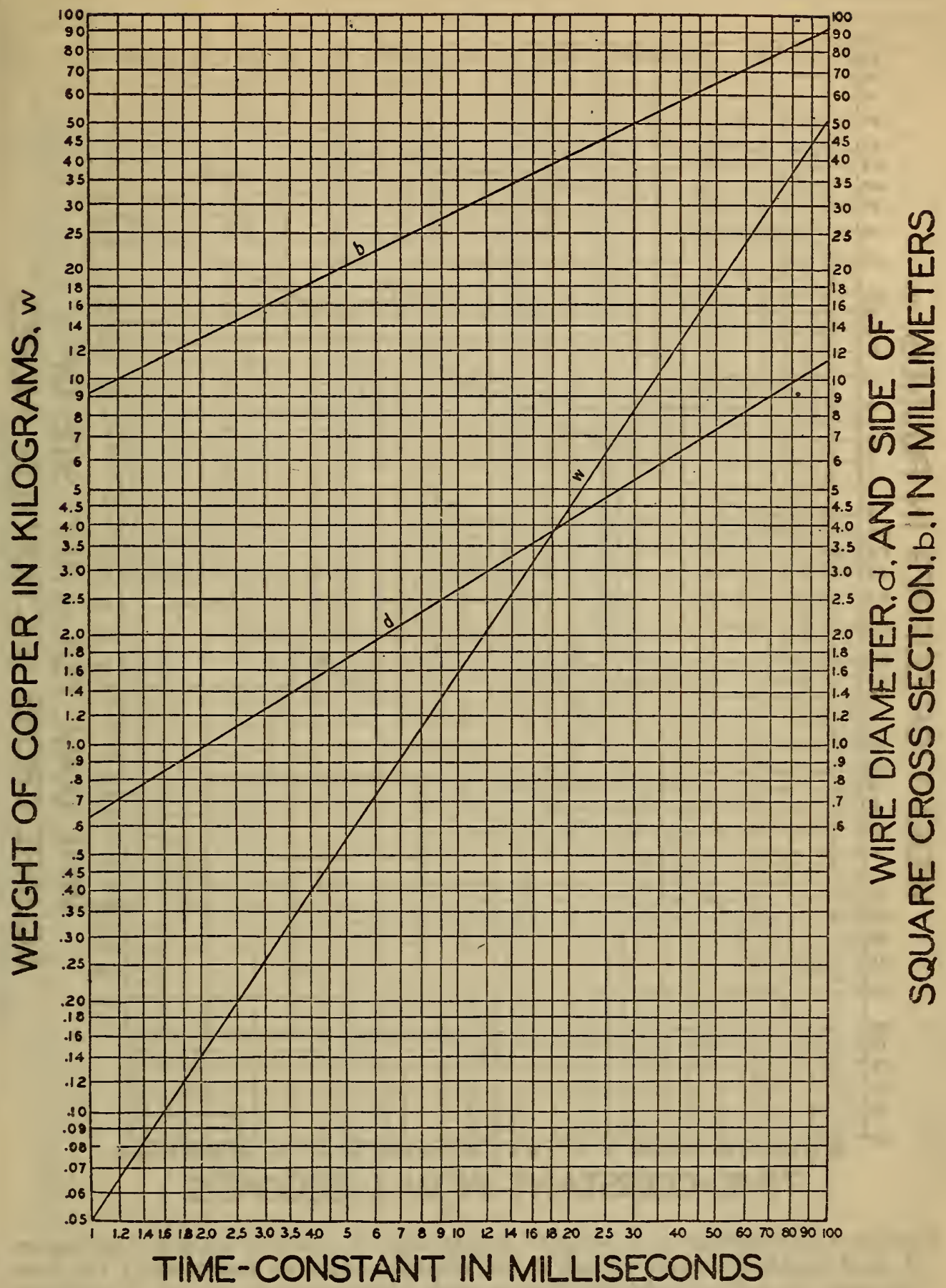

FIGURE 3.-Diameter of wire (over the insulation) $d$, side of square cross section $b$, and weight of copper in coil $w$, in metric units, as functions of the time constant in milliseconds, for circular coils of square cross section of optimum proportions (mean diameter of winding equal to three times the side of the square cross section)

Denoting the time constant in milliseconds by $\tau$, and expressing $b$ and $d$ in millimeters and $w$ in kilograms, the equations of these curves are as follows:

$$
\begin{aligned}
b & =9.142 \tau^{\frac{2}{2}} \\
d & =.6336 \tau^{\frac{3}{8}} \\
w & =.05027 \tau^{\frac{3}{2}}
\end{aligned}
$$

The value of $\tau$ is based on the resistivity of copper of 100 per cent purity at $25^{\circ} \mathrm{C}$., and on the assumptions that ideal insulation of zero thickness is used and that there is no embedding of turns. 


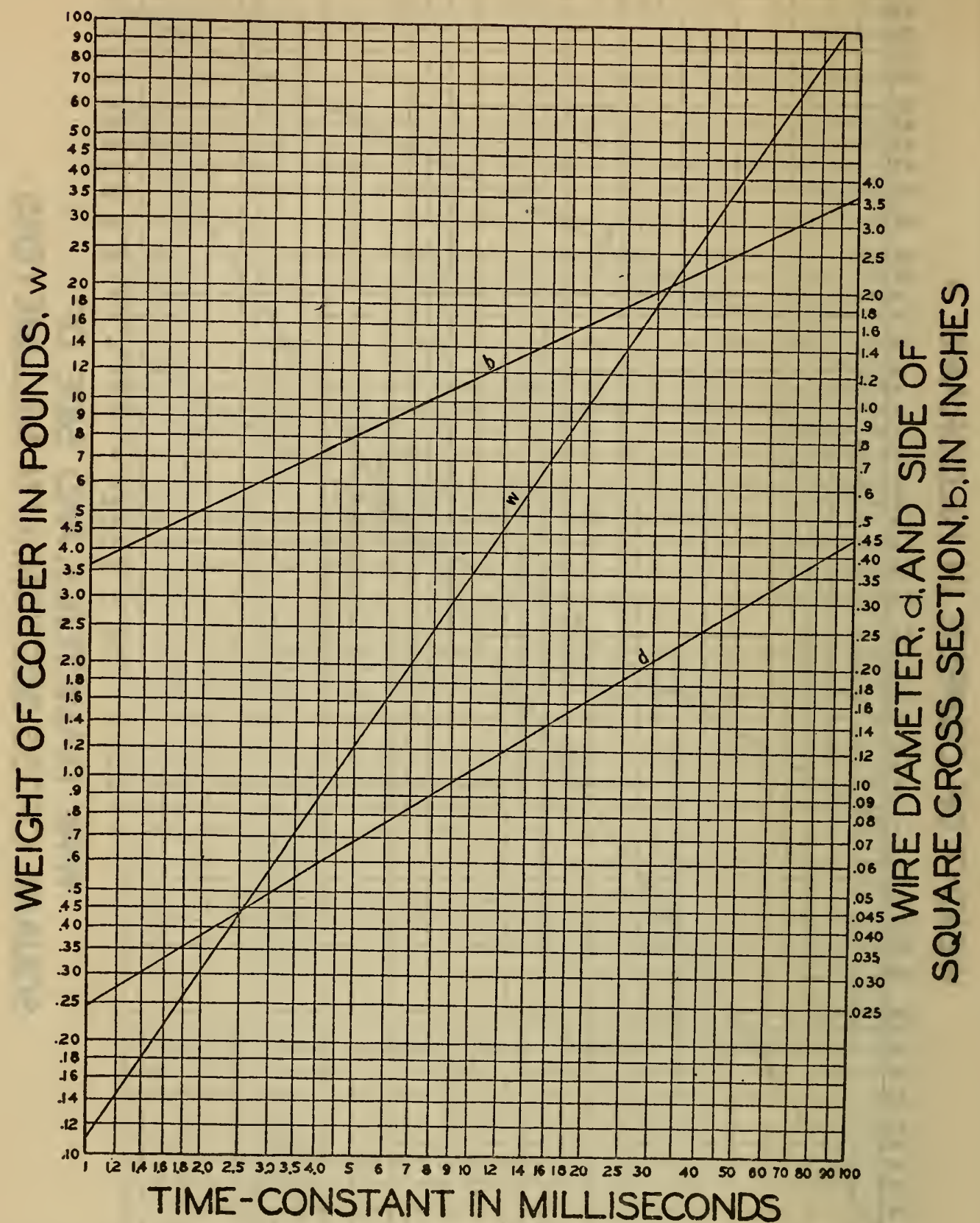

FIGURE 4.-Diameter of wire (over the insulation) d, side of square cross section $b$, and weight of copper in coil $w$, in English units, as functions of the time constant in milliseconds, for circular coils of square cross section of optimum proportions (mean diameter of winding equal to three times the side of the square cross section)

Denoting the time constant in milliseconds by $\tau$, and expressing $b$ and $d$ in inches and $w$ in pounds, the equations of these curves are as follows:

$$
\begin{gathered}
b=0.3599 \tau^{\frac{3}{2}} \\
d=.02494 \tau^{\frac{5}{6}} \\
w=.1108 \tau^{\frac{3}{2}}
\end{gathered}
$$

The value of $\tau$ is based on the resistivity of copper of 100 per cent purity at $25^{\circ} \mathrm{C}$., and on the assumptions that ideal insulation of zero thickness is used and that there is no embediling of turns. 
between the diameters (over insulation) of two adjacent gage sizes. Denoting larger ${ }^{12}$ of these tabular diameters by $d_{1}$, and the thickness of insulation by $t_{1}$, the first revision factor $\tilde{d}_{1} /\left(d_{1}-2 t_{1}\right)$ is computed. (The quantity $d_{1}-2 t_{1}$ is the diameter of the bare wire, and can usually

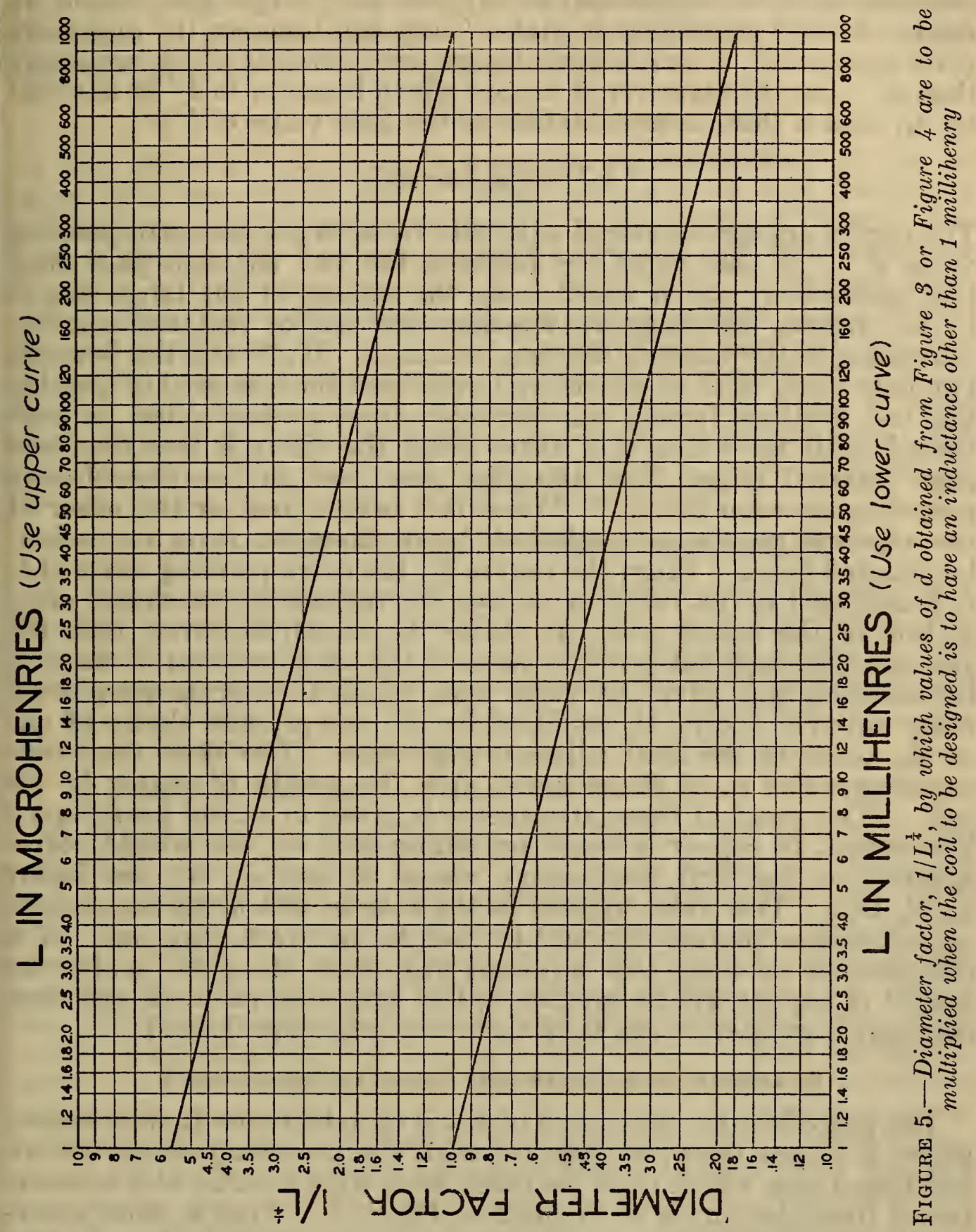

be taken directly from the table). Then a second approximation for $b$ is

$$
b^{\prime \prime}=b^{\prime} d_{1} /\left(d_{1}-2 t_{1}\right)
$$

Again referring to the curves, and entering with the value of $b^{\prime \prime}$, the corresponding value of wire diameter $d^{\prime \prime}$ is read off. If this should happen to coincide with $d_{1}$, wire of this diameter (over insula-

12 Even if $d^{\prime}$ coincides with the diameter (over insulation) of a gage size, the diameter of the next larger gage size should be used as $d_{1}$. 
tion) should be used; the value of $b^{\prime \prime}$ gives the side of the square cross section of the coil, and the mean radius of the coil is $a=1.5 b^{\prime \prime}$. If the second approximate value $d^{\prime \prime}$ should fall between $d_{1}$ and the next larger gage size, $d_{1}$ may be chosen if some sacrifice in time constant may be considered; if not, the next larger size should be used. A third possibility is that $d^{\prime \prime}$ may fall between the diameters (over insulation) of two adjacent gage sizes, both of which are larger than $d_{1}$. Let the diameter of the one which is nearer to $d^{\prime \prime}$ be denoted by $d_{2}$; then a third approximation to the final value of $b$ is

$$
b^{\prime \prime \prime}=b^{\prime} d_{2} /\left(d_{2}-2 t_{2}\right)
$$

The curves are again entered with this value to get the corresponding value $d^{\prime \prime \prime}$. If this value lies between the two adjacent gage sizes just mentioned, one of which is $d_{2}$, the smaller or the larger size is to be chosen, according to whether one can or can not sacrifice something in the value of the time constant. If $d^{\prime \prime \prime}$ still lies between two gage sizes, both of which are larger than the size used in forming the last revision factor, this approximation process must be continued until the value of $d$ taken from the curve is less than one gage interval larger than the gage size used in the immediately preceding revision factor. ${ }^{13}$ When this occurs, one or the other of the adjacent gage sizes is selected; let its diameter (over insulation) be denoted by $d_{n}$. From the curves $b_{n}$, the corresponding value of $b$, is found, and is the value to be used for the side of the square cross section of the actual coil. It should be noted, however, that the abscissa of $b_{n}$ does not give the value of the time constant of the coil, because this will have the value with which the curves were originally entered, except as modified by the compromise choice of one or the other of the final adjacent gage sizes. Nor does the corresponding value $w_{n}$ of the $w$ curve give the weight of copper in the coil. (The proof of these statements is given in a later paragraph.) The weight of copper is found by multiplying $w^{\prime}$, the weight corresponding to the first preliminary values $b^{\prime}$ and $d^{\prime}$, by the factor $d_{n} /\left(d_{n}-2 t_{n}\right)$. This value applies to the case in which the successiveapproximation process happens to lead to an exact gage size. If a compromise between two adjacent gage sizes must be made, the weight of copper will be greater or less than this value, as the time constant is greater or less than the value originally desired.

\section{(d) DESIGN OF A COIL OF ANY VALUE OF INDUCTANCE}

The procedure for the design of a coil of inductance $L$ millihenries, where $L$ is not unity, is identical with the preceding except for an additional step which must be taken each time a value of $d$ is ascertained from the curves of Figure 3 or Figure 4 . That is, after entering the curves with the desired time constant and obtaining the first preliminary values $d^{\prime}, b^{\prime}$, and $w^{\prime}$, it is necessary to translate $d^{\prime}$ into the diameter for a coil of $L$ millihenries. This is done by using relation (b), page 296 , and to avoid computation the curves of Figure 5

\footnotetext{
13 The necessity for this succession of approximations lies in the fact that even for the same kind of insulation the space factor $\frac{\pi}{4}[(d-2 t) / d]^{2}$ usually varies from one gage size to the next. (This does not always apply to "enamel" insulated wire, for which the space factor is sometimes closely constant over a considerable number of sizes.) For insulations which are wholly or partly fibrous the rate of ehange of the space factor increases as the diameter decreases, and the number of approximations required in the design of inductance coils inereases in eonsequence.
} 
may be used. Entering with $L$ as abscissa, the value of $1 / L^{\frac{1}{2}}$ is obtained and $d^{\prime}$ is multiplied by it to get the first preliminary ( $L$ millihenry) value $D^{\prime}$ of wire diameter. Like $d^{\prime}$ in the 1-millihenry case, this value applies for wire of zero-thickness insulation, and, like $d^{\prime}$, it will ordinarily fall between two adjacent gage sizes. Choosing the larger ${ }^{14}$ of these diameters, and denoting it by $D_{1}$, a second approximation to the final value of $b$ will be

$$
b^{\prime \prime}=b^{\prime} D_{1} /\left(D_{1}-2 t_{1}\right)
$$

To this value $b^{\prime \prime}$ corresponds a second approximation $d^{\prime \prime}$ (to be taken from the curve), and $d^{\prime \prime}$ times the value of $1 / L^{z}$ previously found gives a second approximation $D^{\prime \prime}$ to the diameter (over insulation) of the wire for the desired $L$-millihenry coil. In short, the only difference in procedure, for a coil of $L$ millihenries, is that the value of $1 / L^{\frac{1}{3}}$ should be used between the obtaining of each of the successive values of $b$ and the calculation of the revision factor of the form $D /(D-2 t)$. After the final wire diameter $D_{n}$ is selected, it is to be divided by $1 / L^{\frac{1}{3}}$ to get an equivalent 1 -millihenry value $d_{n}$ with which to enter the curves of Figure 3 or Figure 4 to get the final value $b_{n}$ to be used. The weight of copper is found by multiplying $w^{\prime}$ by the final value $D_{n} /\left(D_{n}-2 t_{n}\right)$ of the revision factor.

\section{(e) DEVIATION OF ACTUAL WIRE FROM TABULAR DATA}

If in any case the wire which is to be actually used for the coil is found to have either of its diameters (namely, over copper and over insulation) appreciably different from the tabular values $d_{n}$ and $d_{n}-2 t_{n}$ used in the design, the actual value $d_{n}$ should be used to find $b_{n}$, and the effect on the time constant of the variation of $d_{n}-2 t_{n}$ should be checked by the method of the next paragraph.

(f) CHECKING THE DESIGN VALUES; TAKING CARE OF VARIATIONS

The theoretical number of turns $N$ in the coil will be $b_{n}{ }^{2} / d_{n}{ }^{2}$, and with this value and that of $a\left(=1.5 b_{n}\right)$ the value of inductance may be checked from the appropriate one of formulas (3) to (8), page 295. The resistance and the time constant may then be calculated. These computed check values involve four assumptions, namely, that the wire has a certain exact diameter, over the insulation; that the relation between $b_{n}$ and $d_{n}$ is such that there is an exactly integral number of turns per layer and the same number of layers; that the winding is close and regular, and that no embedding occurs. In practice it is not possible to control matters so as to produce such an ideal winding, and consequently there must be some means of taking care of the variations from the ideal coil. For this purpose the flanges of the spool upon which the wire is to be wound should preferably be made of a diameter somewhat larger than merely enough to accommodate a winding of square cross section. Figure 6 shows the manner of variation of inductance of a coil of fixed axial length of winding when the radial depth of winding is changed from 20 per cent less to 20 per cent more than the depth for a square cross section.

In the case of coils of relatively low inductance, in which there are relatively few turns per layer, the value $b_{n}$ finally chosen should

16 Even if $D^{\prime}$ coincides with a gage diameter, the diameter (over insulation) of the next larger gage size should be taken as $D_{1}$. 
be increased slightly, if necessary, to accomodate an integral number of turns per layer.

Adjacent sizes of wire, American Wire Gage, differ in diameter by the factor 1.123. By relation (b), page 296, two coils of the same dimensions, wound with wires of adjacent gage sizes and of the same space factor, will have inductances in the ratio of $(1.123)^{4}$ to 1 ; that is, 1.6 to 1 . It is almost always necessary to compromise on

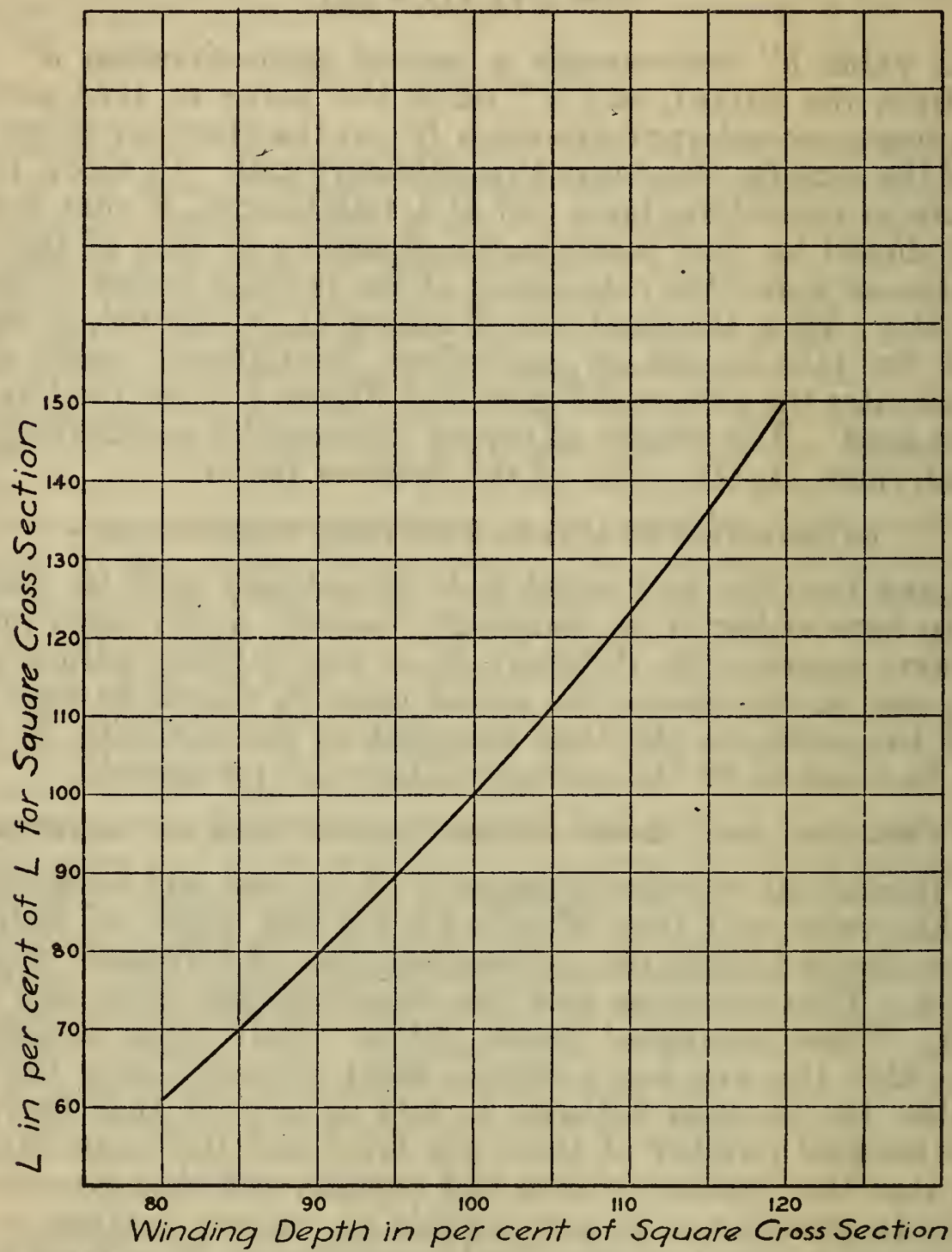

FrgURE 6.-Manner of variation of the self-inductance of a circular coil, nominally of square cross section of optimum proportions (mean diameter of winding equal to three times the side of the square cross section), as the depth of winding progresses from 20 per cent below to 20 per cent above that which forms a square cross section

the nearest gage size because of the inconvenience and expense of having special sizes of wire supplied to order. An obvious alternative, however, is to wind the coil partly of one of the two adjacent sizes and then to complete it with the other size.

The space factor of fine wires with any given kind of insulation is, in general, lower than that of coarse wires; consequently, if a set 
' of inductance coils is to be designed, all to be wound on one uniform size of spool and to have a time constant which in no case shall be less than a prescribed value, the coil of the greatest self-inductance should be designed first and the spool be designed to accommodate it.

\section{(g) TIME CONSTANT AND WEIGHT OF FINAL COIL}

The design curves were entered with a desired value of time constant for which the side of the square cross section is $b^{\prime}$ for wire having zero-thickness insulation. The subsequent steps of the design have led to higher values of $b$, ending with a final value $b_{n}$. The time constant, however, does not increase with $b$, but retains the value with which the curves were originally entered, except as modified by the compromise choice of one or the other of the gage sizes between which $d_{n}$ lies. In the following demonstration of this fact it is assumed for simplicity that wire of diameter $b_{n}$ is available for the coil.

When the preliminary value $b^{\prime}$ is multiplied by the final revision factor $d_{n} /\left(d_{n}-2 t_{n}\right)$, which may be called $K$ for brevity, the area of cross section of the coil is increased by the factor $K^{2}$. Since $d_{n}$ has the same abscissa as $K b^{\prime}$ the inductance of the coil will still be 1 millihenry because the relation of the curves is such that $d_{n}=K^{\frac{s}{3}} d^{\prime}$; see relation $(c)$, page 296 . The mean radius of the coil and hence the mean length of a turn increases by the factor $K$; the number of turns becomes lower by the factor $K^{2} /\left(K^{\frac{s}{4}}\right)^{2}=1 / K^{\frac{1}{3}}$; consequently the total length of wire in the coil becomes greater by the factor $K^{\frac{1}{2}}$. The diameter of the bare wire becomes greater by the factor $K^{\frac{5}{5}} / K=K^{\frac{1}{4}}$, hence its cross-sectional area becomes greater by the factor $K^{\frac{1}{2}}$, which maintains the original value of resistance in spite of the increased length of wire in the coil. The time constant thus remains at its original value.

The mass of copper becomes greater by the product of the factors of increase of length, $K^{\frac{1}{2}}$, and that of increase of area, $K^{\frac{1}{2}}$; that is, the actual coil of wire diameter (over insulation) $d_{n}$ and thickness of insulation $t_{n}$, while of the same resistance and inductance as the ideal coil of wire diameter $d^{\prime}$ with zero-thickness insulation, has a mass of copper which is greater than the ideal value $w^{\prime}$ by the factor $K=d_{n} /\left(d_{n}-2 t_{n}\right)$.

\section{(h) NUMERICAL EXAMPLE OF DESIGN}

A coil of 100 millihenries is to be wound of copper wire insulated with "enamel" and one covering of silk, and is to have a time constant of 3 milliseconds. Required the size of the wire, the dimensions of the coil, and the weight of copper composing it. The curves of Figures 4 and 5 will be used. Entering the curves of Figure 4 with $\tau=3$ milliseconds,

From Figure 5

$$
\begin{aligned}
b^{\prime} & =0.625 \text { inch } \\
d^{\prime} & =0.0495 \text { inch } \\
w^{\prime} & =0.575 \text { pound }
\end{aligned}
$$

whence

$$
1 / L^{\frac{1}{4}}=0.320
$$

$$
\begin{aligned}
D^{\prime} & =0.320 \times 0.0495 \\
& =0.0158 \mathrm{inch}
\end{aligned}
$$


From a table for a particular make of this kind of insulated wire the following data are extracted:

\begin{tabular}{|c|c|c|c|c|}
\hline Size, American Wire Gage & 25 & 26 & 27 & 28 \\
\hline $\begin{array}{l}\text { Diameter bare wire } \\
\text { Diameter over insulation } \\
\text { Resistance at } 25^{\circ} \mathrm{C} \text {. per } 1,000 \text { feet. } \\
\text { Weight per } 1,000 \text { feet }\end{array}$ & $\begin{aligned} 0.0179 \\
.0216 \\
33.0 \\
.970\end{aligned}$ & $\begin{aligned} 0.0159 \\
.0195 \\
41.6 \\
.769\end{aligned}$ & $\begin{aligned} 0.0142 \\
.0176 \\
52.5 \\
.610\end{aligned}$ & $\begin{array}{l}0.0126 \\
.0160 \\
66.2 \\
.484\end{array}$ \\
\hline
\end{tabular}

It may be seen that $D^{\prime}$ nearly coincides with the diameter (over insulation) of No. 28 wire. That of No. 27 is taken as $D_{1}$, and the first value of the revision factor is

Hence

$$
\begin{aligned}
\mathrm{D}_{1} /\left(D_{1}-2 t_{1}\right) & =0.0176 / 0.0142 \\
& =1.239
\end{aligned}
$$

$$
\begin{aligned}
b^{\prime \prime} & =b^{\prime} D_{1} /\left(D_{1}-2 t_{1}\right) \\
& =0.625 \times 1.239 \\
& =0.775 \text { inch }
\end{aligned}
$$

Curve $d$ of Figure 4 is entered with this value and $d^{\prime \prime}$ is found to be 0.0640 inch. Then

$$
\begin{aligned}
D^{\prime \prime} & =0.320 \times 0.0640 \\
& =0.0205 \text { inch }
\end{aligned}
$$

This value lies midway between the figures for No. 25 and No. 26 . For No. 25,

$$
\begin{aligned}
D_{2} /\left(D_{2}-2 t_{2}\right) & =0.0216 / 0.0179 \\
& =1.207 \\
b^{\prime \prime \prime}=b^{\prime} D_{2} /\left(D_{2}-2 t_{2}\right) & =0.625 \times 1.207 \\
& =0.754 \mathrm{inch}
\end{aligned}
$$

Curve $d$ of Figure 4 is entered with this value, and $d^{\prime \prime \prime}$ is found to be 0.0622 inch. Also

$$
\begin{aligned}
D^{\prime \prime \prime} & =0.320 \times 0.0622 \\
& =0.0199 \mathrm{inch}
\end{aligned}
$$

This value lies between the same pair of gage sizes as $D^{\prime \prime}$, hence the choice of the wire to be used for the coil lies between No. 25 and No. 26. $D^{\prime \prime \prime}$ is much closer to No. 26, and the choice of the latter will give a value of time constant which, while below the desired value, will be the closer approximation to it. $D_{3}$ is now taken as 0.0195 inch, from which

$$
\begin{aligned}
d_{3} & =D_{3} /\left(1 / L^{\frac{1}{3}}\right) \\
& =0.0195 / 0.320 \\
& =0.0610 \mathrm{inch}
\end{aligned}
$$

Corresponding to this value in Figure 4 is the value $b_{3}=0.741 \mathrm{inch}$, the value to be used for the side of the square cross section. The mean radius of the coil is $a=1.5 b=1.5 \times 0.741$ equals $1.111 \mathrm{inch}$, and the over-all diameter of the coil is $4 b=2.964$ inches.

Check:

$$
\begin{aligned}
N & =(0.741 / 0.0195)^{2}=1,444 \text { turns } \\
a & =1.111 \mathrm{inch} \\
L & =0.00004274 a N^{2} \\
& =0.00004274 \times 1.111 \times(1,444)^{2} \\
& =99.1 \text { millihenries }
\end{aligned}
$$


The length of wire in the coil is

$$
\begin{aligned}
2 \pi a N & =6.283 \times 1.111 \times 1,444 \\
& =10,085 \text { inches } \\
& =840 \text { feet }
\end{aligned}
$$

The resistance at $25^{\circ} \mathrm{C}$ is

$$
\begin{aligned}
R & =0.840 \times 41.6 \\
& =34.9 \mathrm{ohms}
\end{aligned}
$$

and the time constant is

$$
\begin{aligned}
\tau & =L / R \\
& =99.1 / 34.9 \\
& =2.83 \text { milliseconds }
\end{aligned}
$$

The weight of copper in the coil is

$$
0.840 \times 0.769=0.646 \text { pound }
$$

If No. 25 wire had been chosen, the following results would be obtained:

$$
\begin{aligned}
d_{3} & =0.0216 / 0.320 \\
& =0.0675 \text { inch }
\end{aligned}
$$

From Figure 4, for this value of $d_{3}$

Check:

$$
b_{3}=0.802 \text { inch }^{\prime}
$$

$$
\begin{aligned}
N & =(0.802 / 0.0216)^{2}=1,379 \text { turns } \\
a & =1.5 b=1.5 \times 0.802 \\
& =1.203 \text { inch } \\
L & =0.00004274 \times 1.203 \times(1,379)^{2} \\
& =97.7 \text { millihenries }
\end{aligned}
$$

The length of wire in the coil is

Its resistance at $25^{\circ} \mathrm{C}$. is

$$
\begin{aligned}
2 \pi a N & =6.283 \times 1.203 \times 1,379 \\
& =10,420 \text { inches } \\
& =868 \text { feet }
\end{aligned}
$$

$$
0.868 \times 33.0=28.66 \mathrm{ohms}
$$

and its time-constant is

$$
\begin{aligned}
\tau & =97.7 / 28.66 \\
& =3.41 \text { milliseconds }
\end{aligned}
$$

The weight of copper in the coil is

$$
0.868 \times 0.970=0.842 \text { pound. }
$$

(i) DESIGN OF A COIL OF GIVEN INDUCTANCE TO FILL A GIVEN SPOOL

If a spool of the optimum proportions of given size is to be wound to have a given inductance, the curve $b$ is entered with the value of $b$ for this spool. The corresponding value of $d$ gives the diameter of the wire (over the insulation) to be used for an inductance of 1 millihenry. For any other value of $L$ this value of $d$ is to be multiplied by the appropriate value of $1 / L^{*}$ from Figure 5 .

$64825-31-7$ 
(j) DESIGN OF A COIL OF GIVEN INDUCTANCE, OF WIRE OF GIVEN DIAMETER

In this case, for a coil of 1 millihenry, the curve $d$ is entered with the given diameter of wire (over the insulation) and the corresponding value of $b$ is the side of the square cross section of the coil. For a coil of $L$ millihenries, the given diameter is first to be multiplied by $L^{\frac{1}{*}}$; that is, divided by the value of $1 / L^{\frac{1}{2}}$ taken from one of the curves of Figure 5.

\section{(k) DATA FOR THE PLOTTING OF THE DESIGN CURVES}

The curves of Figures 3 and 4, plotted on large sheets of logarithmic coordinate paper, will permit more convenient interpolation than is possible with the small-scale figures of this paper. The curves are nominally straight lines having the following equations, in which $b, d$, and $w$ have the same meanings as in Figures 3 and 4 , and $\tau$ denotes the time constant in milliseconds:

Metric units; $b$ and $d$ in $\mathrm{mm}, w$ in $\mathrm{kg}$ :

$$
b=9.142 \tau^{\frac{1}{2}}, d=0.6336 \tau^{\frac{k}{3}}, w=0.05027 \tau^{\frac{3}{2}}
$$

English units; $b$ and $d$ in inches, $w$ in pounds:

$$
b=0.3599 \tau^{\frac{1}{2}}, d=0.02494 \tau^{\frac{5}{3}}, w=0.1108 \tau^{\frac{3}{3}}
$$

The numerical coefficients in these six equations are based on the following data: Density of copper, 8.89 ; resistance between opposite faces of a centimeter cube of copper at $25^{\circ}$ C., 1.757 microhms. (These figures correspond to 100 per cent conductivity, International Annealed Copper Standard.)

Because of slight imperfections in the coordinate paper, it is best to plot more than two points and to draw the curve through the plotted points rather than as a strictly straight line. Each of the curves of Figures 3 and 4 was drawn through computed points for $\tau=1,3,10,30$, and 100 milliseconds. These computed values are

\begin{tabular}{|c|c|c|c|c|c|}
\hline & 3 & & 30 & 100 & \\
\hline & 15.83 & & 50.1 & & \\
\hline & & & & & \\
\hline 63 & 1.2 & & 5.3 & 11. & \\
\hline$=$ & & & & & \\
\hline$=$ & & & & & \\
\hline & & & 18.2 & 110. & \\
\hline
\end{tabular}
as follows:

(1) ADJUSTMENT OF THE STANDARD TO ITS NOMINAL VALUE

Since the two binding posts are preferably to be located close together in order to avoid forming a loop when making connections to the standard, one is, in general, restricted to an integral number of turns. In general, therefore, a coil of $N$ turns would have to be left with an error of $1 / N$ part ${ }^{15}$ of its nominal value. For coils of a large number of turns this degree of precision of adjustment may be sufficient. Where the number of turns and the inductance are small,

\footnotetext{
1s The worst case would be where the nominal value required that the number of turns differ from an integral number by one half-turn; since the inductance varies as the square of the number of turns, the effect of a half-turn in $N$ turns is one part in $N$ in inductance. This is an approximate statement only, because the effect of an outside turn is, in general, different from that of a mean turn.
} 
some means for obtaining closer adjustment is necessary. One way of doing this is illustrated in Figure 7. A circular recess is made in the spool, into which opens the small hole, through which the starting end of the wire is passed. After the coil is wound, and adjusted to the nearest whole (outside) turn for which the inductance is either a little low or a little high, the wire near the starting end may be made into a little coil within the recess, in inductive relation to the main coil, and any desired precision of adjustment obtained. This method also provides for subsequent readjustment if necessary. The small coil may be protected from derangement by a suitable cover for the circular recess in which it lies.

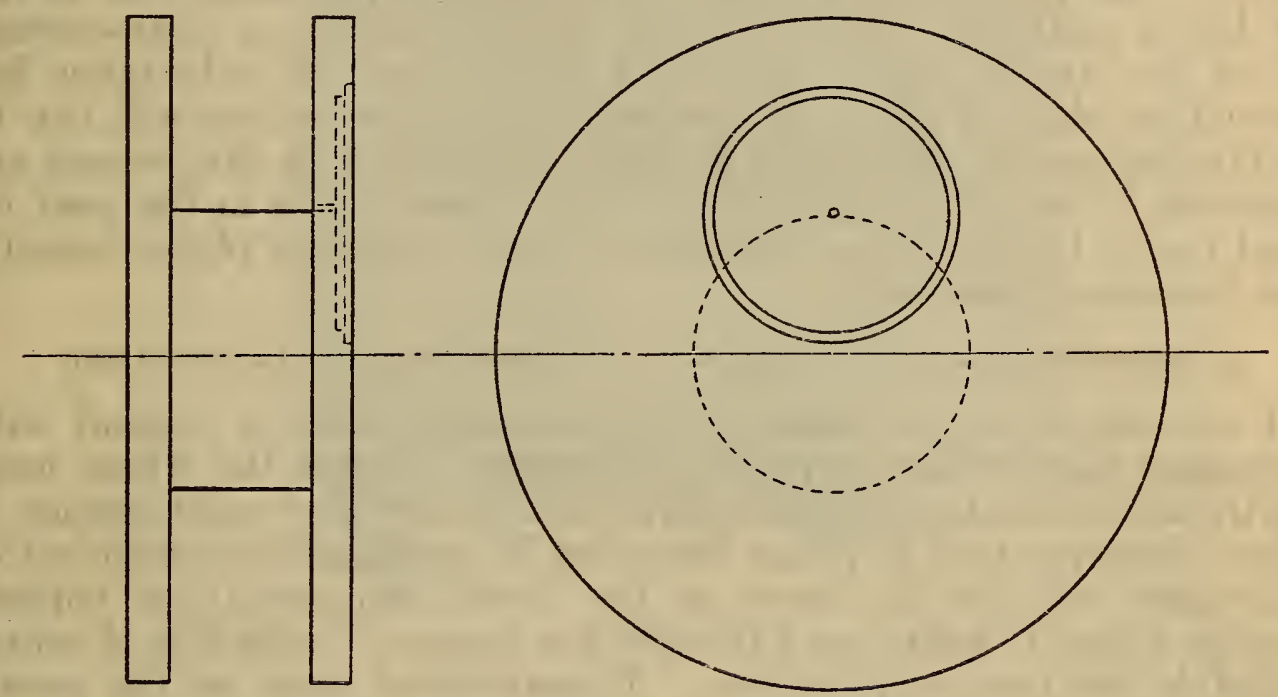

FIgURE 7.-Form or spool for standard of self-inductance, showing circular recess within which the inner end of the winding may be coiled to effect the final precise adjustment of inductance.

(m) MATERIALS FOR THE SPOOL; BINDING POSTS

Coils to be used as standards of inductance have been wound on forms or spools of various materials. Mahogany saturated with paraffine has been used to a limited extent. German makers at one time used serpentine, but in the case of certain coils, this was later shown ${ }^{16}$ to be slightly magnetic and, therefore, unsuitable. White marble is free from this defect, and its expansivity appears to be close to the desirable value, but it has the undesirable property of irreversible growth ${ }^{17}$ when heated above room temperature.

Porcelain 1-piece spools have been used to a limited extent. Porcelain has valuable properties for this purpose. The linear expansivity of various kinds of porcelain has been found ${ }^{18}$ to vary from about 3 to 20 parts per million per degree C., a range which includes the value for copper. Porcelain of such composition as to have approximately the expansivity of copper should be very suitable. Porcelain is free from the phenomenon of growth noted in marble.

Phenol condensation products, such as bakelite, condensite, etc., as a rule, have expansivities exceeding that of copper, and they shrink if kept at temperatures above $60^{\circ} \mathrm{C}$. The expansivity of mahogany

16 Rosa and Grover, B. S. Bull. 3, pp. 337-348; 1907; Reprint No. 15.

17 Souder and Hidnert, B. S. Bull. 15, pp. 411-416; 1919-20; Sci. Paper No. 352

18 Souder and Hidnert, B. S. Bull. 15, pp. 391-398; 1919; Sci. Paper No. 352. 
across the grain is more than twice that of copper; with the grain, about one-fifth that of copper. All untreated woods are, of course, objectionable because they change form as their moisture content changes. Hard rubber and vulcanized fiber are objectionable because their expansivities are four or five times those of copper, and vulcanized fiber swells and warps when exposed to moist air.

While the size and location of binding posts is usually a matter of mere convenience and appearance in most electrical apparatus, it is not so in the case of standards of inductance. To minimize the effect of eddy currents the binding posts should be made of metal of high resistivity and should be as small as is consistent with other requirements. The posts should be located where the magnetic field of the coil has a relatively low value, not only to minimize eddy-current effects but also in order to keep down the mutual inductance between the coil and any loop formed by the wires which will run to the binding posts. Examples of good construction in this respect are standards $G$ and $H$ in Figure 2. Some makers have in the past located heavy brass binding posts in the worst possible place, namely, near the axis of the coil.

(n) TEMPERATURE COEFFICIENT OF STANDARDS OF INDUCTANCE

If the copper in an inductance standard is free to expand with increasing temperature, without constraint, so that the whole mass of wire and insulation changes form as it would if of solid copper, it follows from relation $(g)$, page 296, that its temperature coefficient of inductance will be the same as the linear expansivity of copper, namely, about 17 parts per 1,000,000 per degree C., which is of course negligible for most applications. Experimental data on the actual temperature coefficient of inductance standards seem to be lacking.

(o) SETS OF INDUCTANCE COILS

When a number of inductance coils are to be assembled in a box, they should be arranged so that the mutual inductance between coils will be very small. Three coils, assembled in a row with their planes mutually perpendicular will have zero mutual inductance between any pair. After the first coil is mounted in position, the second coil can be readily located in the position of zero mutual inductance by passing an alternating current through the first coil, attaching a telephone receiver to the second coil, and securing the latter in a position such that there is no sound in the receiver. Then each of the first two coils can be used as a primary and the third coil can be located in the position which gives silence in the receiver in each case. A fourth coil can be located to have zero mutual inductance with respect to coils 2 and 3 but necessarily has some mutual inductance with coil 1 . However, the mutual inductance between two coils decreases very rapidly ${ }^{19}$ as their distance apart increases.

Figure 8 shows a set of 8 standards of self-inductance, consisting of 2 rows of 4 coils, each row being mounted in the manner just described. To reduce mutual inductance between the coils of one row and those of the other to a negligible amount, the rows are separated as shown. Eight noninductive copper coils also are provided, each adjusted to have the same resistance as one of the induc-

${ }^{10}$ A pproximately, the mutual inductance varies inversely as the cube of the distance between the coils, when this distance is large compared with the diameter of the coils. 


\section{B. S. Journal of Research, RP342}

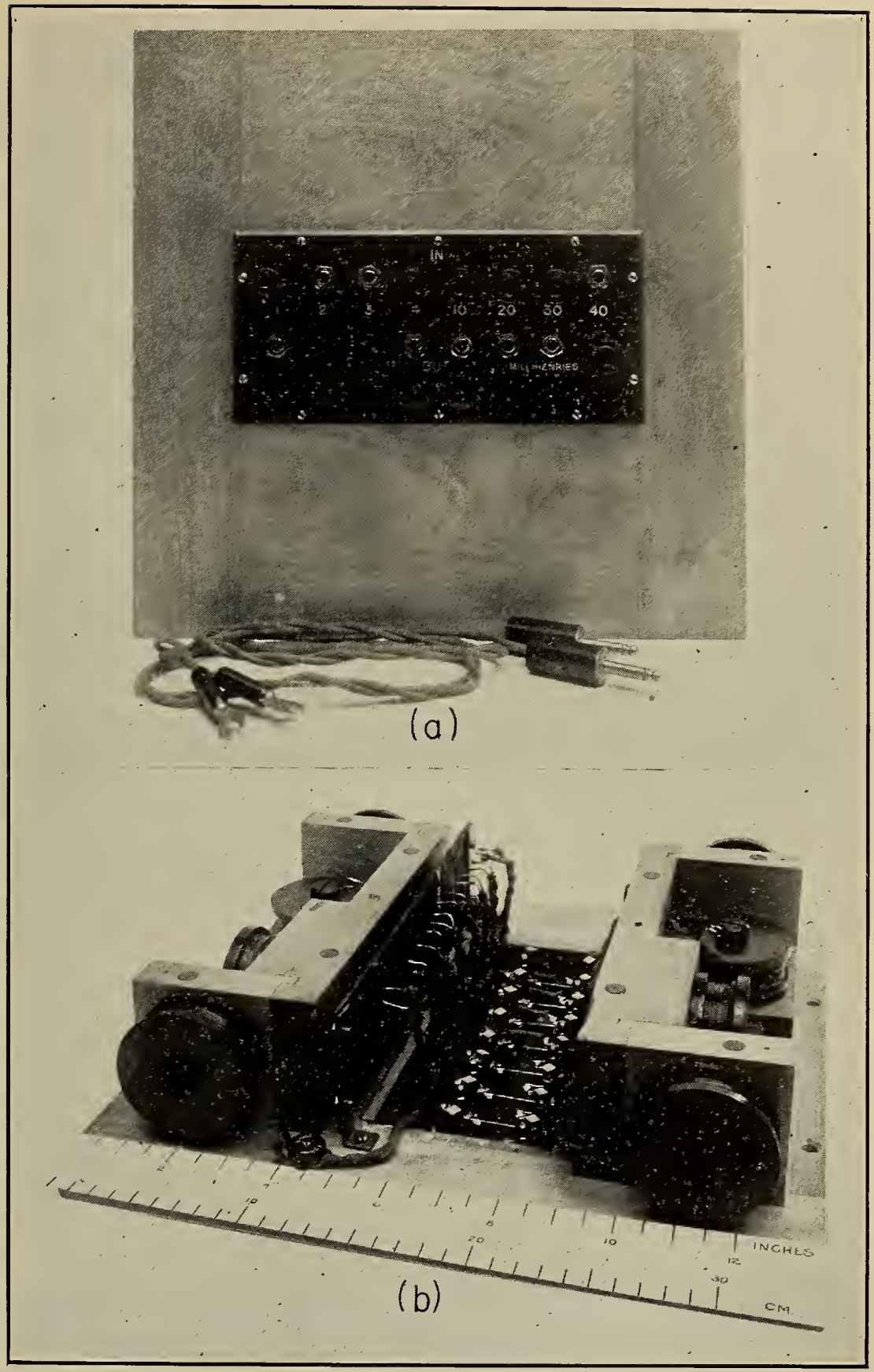

Figure 8.-Set of eight standards of self-inductance

$a$, Complete in case; $b$, removed from case. The coils in one row have the values $1,2,3$, and 4, millihenries; in the other, $10,20,30$, and 40 millihenries. The coils in each row are located to minimize mutual inductance between coils, and the two rows are spaced far enough apart to make mutual inductance between rows negligibly small. The pair of flexible leads with "traveling plugs" is for use when connection is to be made (for special purposes) to one or several of the individual coils. 
tive coils. The plug switchboard makes it possible to cut into circuit any one or more of the inductive coils and to replace those out of circuit by their corresponding noninductive coils. The total resistance between the terminals is thus kept constant, regardless of the value of the inductance. This feature is convenient when the set is used in one arm of an inductance bridge. The switchboard is composed of regular commercial radio parts, namely, 16 "short jacks" and 8 "duplex plugs." Each of these plugs has its two contact parts (tip and sleeve) short-circuited within the handle. A plug inserted in any hole in the upper row (marked "In") inserts the correspondingly numbered inductive coil; in thelower row, the noninductive coil.

In some cases it is desirable to use one or several of the inductive coils of the set without including in the circuit any unnecessary resistance. The flexible leads shown in Figure 8 are for this purpose. One lead is connected to the tip of its plug, the other to the sleeve of its plug. Single coils, either inductive or noninductive, may be picked out with these "traveling plugs." If several coils in series are wanted, the traveling plugs are used in conjunction with one or more of the regular (short-circuited) plugs. Other connections are possible; for example, connections may be made to any coil to be used as a primary coil and to any other to serve as a secondary. This permits the checking of the mutual inductance between the coils to see whether it is sufficiently low (with respect to the sum of their self-inductances) to be negligible.

As compared with an equal number of single standards of inductance, such a set of standards has the advantage that the mutual inductance between each coil and every other one is small and fixed. In using a number of single standards care must always be exercised to keep them far enough apart to make the mutual inductance negligible; and this precaution may easily be neglected by inadvertence. The set of coils has the further advantage of requiring less table space when in use. It has two disadvantages, namely, the greater storage space occupied when the set is not in use, and the fact that the individual coils can not be used in different places on occasion.

Two sets of inductance coils, of much larger dimensions than the ones shown in Figure 8, are used in the current-transformer laboratory of the National Bureau of Standards in the setting up of artificial burdens. With 8 coils ranging from 10 to 500 microhenries, any value of inductance from 10 to 1,100 microhenries can be used. To obtain the highest practicable time constant with a given cost for copper, the coils were wound with square ${ }^{20}$ copper wire. The timeconstants range from 2.5 milliseconds for the 10 -microhenry coil to 17 milliseconds for the 500-microhenry coil.

\section{CURRENT-LIMITING REACTORS FOR POWER SYSTEMS}

\section{SPECIAL REQUIREMENTS}

Inductance coils of large size, known as current-limiting reactors (protective reactors), must meet certain extraordinary requirements which make it impracticable to construct them in the closely wound form described in the preceding section of this paper. In spite of

20 The side of the square cross section of the wire is 0.162 inch. 
the fact that a high time constant is just as desirable in a protective reactor as in an inductance standard for laboratory purposes, and that departure from the optimum form involves an extra cost for copper for a given inductance, the other considerations compel a deviation from the optimum form. These requirements and their effect on the design of protective reactors will be briefly mentioned.

\section{(a) ABILITY TO WITHSTAND HEATING CAUSED BY HEAVY OVERLOADS}

A protective reactor is of service only in an emergency, namely, in case of a heavy overload or a short-circuit on the line in which it is placed. It must be able to carry currents of the order of 25 times rated current for, say, five seconds. During this interval the rate of development of heat in the reactor winding is approximately 625 times its usual value. It is obvious that instead of the closely wound turns and layers of the inductance standard used in the laboratory the protective reactor must have its turns and layers spaced apart to allow free passage of air either by convection or forced circulation.

(b) ABILITY TO WITHSTAND DESTRUCTIVE FORCES DURING SHORT-CIRCUITS

Like the heating effect, these forces increase as the square of the current, and require the use of strong constructions. The turns and layers may be spaced apart and held by strong cleats of heat-resisting insulating material, or they may have concrete supports cast around them.

\section{(c) HIGH FLASH-OVER VOLTAGE}

Although the voltages from turn to turn and layer to layer are relatively small during normal operation, they attain large values during short-circuits or transient disturbances of high frequency. The spacing between turns and layers serves not only to permit escape of heat, but provides the necessary separation to avoid flash over.

(d) LOW SKIN-EFFECT RESISTANCE RATIO

This requirement is important to minimize the copper loss in the reactor during normal operation. Stranding the conductor, and in some cases enameling ${ }^{21}$ certain combinations of the cable strands, are used for this purpose. When several cables are used in parallel to form the reactor winding they are symmetrically spaced and wound so that the total current will be equally divided and circulating currents will be aroided.

\section{DESIGN PROCEDURES IN USE}

The inductance of current-limiting reactors is determined in some cases by means of standard formulas, ${ }^{22}$ such as those of Lorenz, Nagaoka, Rosa, Stefan, and Grover, and in other cases by means of formulas which, while based on standard formulas, also involve the use of families of curves from which values may be found by inter-

\footnotetext{
${ }^{21}$ Robert B. George, The A pplication of Current-limiting Reactors, Electric J., 26, pp. 29-38; January, 1929.

${ }_{22}$ Lorenz's formula is given as equation (74), p. 118; Nagaoka's formula, equation (75), p. 119; Stefan's formula, equation (90), p. 137; Rosa's correction formula, equation (91) p. 139; all of B. S. Sci. Paper No. 169 (part of vol. 8); Grover's formula No. 4 is given on p. 458 of B.S. Sci. Paper No. 455 (part of vol. 18). See also paper by Grover on Formulas and Tables for the Calculation and Design of Single-Layer Coils, Proc. Inst. Radio Engrs., 12, pp. 193-208, A pril, 1924.
} 
polation with an accuracy sufficient for engineering purposes. ${ }^{23}$ The consideration of these methods is outside the scope of the present paper, in which it is desired to suggest the possible uses of small model coils made to scale. The standard formulas usually involve considerable calculation, and for some forms of coil do not converge rapidly enough; the sets of curves may not cover the particular proportions of length and diameter of coil and spacing of conductors for a proposed new and different design; the mutual inductance between adjacent reactors is not easy to calculate and introduces an unbalancing of phase voltages ${ }^{24}$ and the internal short-circuit forces ${ }^{25}$ and those between neighboring reactors are not readily calculated. In all of these matters it is felt that laboratory measurements on model reactors may be useful, not only in checking design values obtained by present methods, but also for determining quantities (such as skin-effect resistance ratio) which are not only difficult to compute in advance, but also difficult to measure in the actual reactors.

\section{USEFULNESS OF MODELS TO DESIGNERS IN VARIOUS FIELDS ${ }^{24}$}

Many problems of engineering design are too complicated for solution by ordinary mathematical methods and must be solved by experiment; but it often happens that the desired information can be obtained from inexpensive experiments on small models quite as well as from full-scale tests.

The classical example of this is the utilization by naval architects of the results of towing-tank experiments on models for predicting the resistance-speed curves of proposed ships; and in recent years the progress of airplane design has been largely dependent on information obtained from tests of models in the wind tunnel. Similar methods have also been used for studying the erosion of stream beds near dams or bridge piers, the formation of sand banks in tidal estuaries, etc.

Model experiments are particularly useful in hydraulics and aerodynamics because the mathematical treatment of the problems that arise nearly always presents insuperable difficulties; but the utility of the method is not confined to the field of fluid motion or of mechanics in general-it is also applicable to many problems in electrical and heat engineering, and it is believed that experiments on small models may be of service to the designer of large commercial reactors.

Whatever the shape or general design of an electrical apparatus may be, its mechanical and electromagnetic properties depend on its absolute size and will be affected in definite ways by a mere change of scale of the whole apparatus, in all its parts, without changing the materials of construction. For the planning and correct interpretation of model experiments the designer, therefore, needs a number of relations connecting the various characteristics in which he is interested with the size, when the shape, number of windings, etc., are fixed.

${ }^{23}$ See H. B. Dwight, Elec. J., 15, pp. 166-168; 1918; Trans. Am. Inst. Elec. Engrs., 38, pt. 2, pp. 1678-1696; 1919; Elec. J., 19, pp. 268-270, 1922; S. L. Oesterreicher, Trans. Am. Inst. Elec. Engrs. 43, pp. 892-901; 1924; A. Ytterberg, Elektrot. Zeit., 36, pp. 309-311, 325-327; 1915; O. Gramisch, Elektrot. und Masch., 46, pp. 105-110; 1928; J. Hak. Elektrot. Zeit., 50, pp. 193-198; 1929; K. Faye-Hansen, Elektrot. Zeit., 51, pp. $427-429 ; 1930$

21 H. B. Dwight, Trans. A. I. E. E., 38, pt. 2, pp. 1679-1681, 1919.

${ }_{25}$ W. M. Dann, The Mechanical Stresses in Reactance Coils, Elec. J., 11, pp. 204-207; 1914; H. B. Dwight, Repulsion and Mutual Inductance of Reactors, Elec. World, 69, pp. 1148-1150; 1917; and Trans. Am. Inst. Elec. Engrs., 38, pt. 2, pp. 1681-1684; 1919.

${ }^{30}$ This section has been eontributed by Dr. E. Buckingham, to whom the writer is indebted for valuable suggestions for the improvement of this paper. 


\section{SUGGESTED USE OF MODELS IN THE DESIGN OF CURRENT- LIMITING REACTORS}

(a) USEFUL RELATIONS

Most of the relations needed in this part of the paper have been given in Part II (p.296) as relations ( $a$ ) to (k), inclusive, and in the following discussion of the uses of models they will be referred to by these letters. In applying these relations to the case of protective reactors, however, an important distinction between these reactors and the small standards of inductance previously discussed should be kept in mind, namely, that the latter (for the relatively low frequencies considered in this paper) are closely wound with insulated wire, so that the diameter of the wire over the insulation has a direct relation to the number of turns to fill a given channel. Protective reactors, on the contrary, usually have air spaces between adjacent turns and adjacent layers. The diameter of the wire over the insulation (if any) has, therefore, no direct relation to the inductance of the coil. However, relations $(b),(c),(e)$, and $(h)$ will still apply if for the "diameter over the insulation" one substitutes the square root of the product of the axial pitch by the radial pitch. ${ }^{27}$ If we define the space factor of a reactor as the ratio of the net cross section of the conductor to the area of a rectangle of which the sides are, respectively, the axial pitch and the radial pitch, relations $(e),(f),(i),(j)$, and $(k)$ apply to coils in which open spaces separate turns and layers.

Another important distinction between the inductance standard and the current-limiting reactor must be noted. The diameter of the wire used in the former is usually so small (with respect to the frequency range to which this paper is limited) that the increase of resistance from skin effect is not serious. In current-limiting reactors, however, the wires or cables are often of relatively large cross section and the skin-effect resistance ratio may be of considerable importance even at the relatively low frequencies on which they are used, since the $I^{2} R$ loss in the reactor during normal operation is proportional to it. The direct measurement of the $I^{2} R$ loss is a somewhat difficult matter because of the large currents and the very low power factor. A special procedure, which will be described later, makes it possible to produce and measure, in the model reactor, a skin-effect resistance ratio equal to that in the full-size reactors.

Current-limiting reactors, in this country, are usually connected in circuits of frequency not exceeding 60 cycles per second, consequently the effect of distributed capacitance may be neglected, so far as effects of operating frequency are concerned.

(b) CHECKING THE SELF-INDUCTANCE OF FULL-SIZE REACTORS

To check the predetermined value of self-inductance of a proposed reactor, a model reactor is made in which all significant dimensions are $1 / n$ times those of the proposed reactor. This factor applies to the copper conductor as well as to the axial length of coil, diameters of successive layers, etc. The conductor should be stranded in the same manner as the full-size conductor will be, in order that the same

27 For coils in which the conductor is wound as a succession of layers the axial pitch is the distance from center to center of adjacent turns in a layer, measured in a direction parallel to the axis of the coil, and the radial pitch is, in general, the radial distance between adjacent imaginary cylinders which are coaxial with the coil, each cylinder bisecting the cross section of the conductors of a given layer. The terms axial pitch and radial pitch may be applied, with obvious modifications, to coils which are wound as a series of coarial fat spirals or "pancakes." 
model may be used to get the skin-effect resistance ratio also. The number of turns in the model should be the same as in the proposed reactor. Then by relation $(g)$, page 296 , the inductance of the fullsize reactor will be $n$ times that of the model. Neglecting skin effect, the $d$. c. resistance of the full-size reactor will be $1 / n$ times that of the model. This resistance, however, can be so easily computed for the full-size reactor that there would be no object in making a model, so far as it is concerned.

(c) CHECKING THE SKIN-EFFECT RESISTANCE RATIO OF FULL-SIZE REACTORS

To determine the skin-effect resistance ratio for the full-size reactor, this ratio is determined for the model, using a frequency $n^{2}$ times the rated frequency of the full-size reactor. ${ }^{28}$ The use of this value of frequency depends upon the fact that the skin-effect resistance ratio (that is, the ratio of a. c. resistance to d. c. resistance) for a conducting structure is a function of one parameter, $f d^{2} \mu / \rho$, where $f$ denotes the frequency, $d$ a given linear dimension, $\mu$ the permeability (equal to unity for air and for copper) and $\rho$ the resistivity of the conductor material. While the form of the function depends on the shape of the structure, this form is the same for all geometrically similar structures of any size or material.

For example, if the proposed full-size reactor is to operate at 60 cycles, and the model is made with each linear dimension one-tenth that of the full-size reactor, the model should be tested for skineffect resistance ratio at 6,000 cycles. It should be noted that in this case it is especially important that the model be wound with a conductor which has the same number of strands (or straps) as the conductor of the full-size reactor, each strand (or strap) having its dimensions $1 / n$ times those of the conductor of the full-size reactor. The arrangement of the winding and the number of turns must be the same in the model as in the full-size reactor. If the individual components of the full-size conductor are insulated from each other, those of the conductor on the model should also be insulated, and the over-all dimensions of the conductor on the model should be $1 / n$ of those of the full-size conductor. While these precautions involve some extra pains in construction, the result of the test gives a figure which would otherwise have to be found by the difficult procedure of measuring the very low power factor of the large current of the full-size reactor.

If it should not be convenient to make the test of the model reactor at $n^{2}$ times the working frequency, it may be made at a different frequency and corrected by using the fact that $\Delta r / r$, the relative increase of resistance caused by skin effect, varies for low frequencies almost exactly as the square of the frequency, and that $\Delta L / L$, the relative change of inductance with frequency, is usually very small compared with $\Delta r / r$.

It is worth noting, as pointed out by Dwight, that the preceding use of a model is applicable to other cases where the inductance and the skin-effect resistance ratio of large conducting structures, for example, busbars and furnace leads, are of importance and are not readily predetermined by calculation.

28 This expedient was suggested by H. B. Dwight, Trans. Am. Inst. of Elec. Engrs., 37, pt. 2, p. 1399; 1918. A more mathematical proof of the theorem was given by Joseph Slepian in the discussion of Dwight's paper, same volume, pp. 1401-1403. 
(d) CHECKING THE MUTUAL INDUC'TANCE BETWEEN FULL-SIZE REACTORS

If a small-scale model of two or more reactors is made with all the dimensions, ${ }^{29}$ including the distances between the reactors, reduced to $1 / n$ times their original values, the number of turns in each model reactor being the same as in the corresponding full-size reactor, the mutual inductance between any pair of reactors will be $1 / n$ times the mutual inductance between the corresponding full-size reactors. The mutual inductance is so nearly independent of frequency ${ }^{30}$ that its value may be determined with any convenient frequency.

The practical importance of a knowledge of the mutual inductance between protective reactors depends mainly on two effects which it produces. The first of these is an unbalancing of phase voltages for cases where the reactors $A, B$, and $C$, are unsymmetrically grouped; that is, where the three mutual inductances $M_{A B}, M_{B C}, M_{A C}$ are unequal. As examples of usual unsymmetrical groupings may be mentioned, first, all three reactors having a common vertical axis; second, all three axes vertical and in a common vertical plane, and the centers of the coils in the same horizontal line. ${ }^{31}$

\section{(e) CHECKING THE ILECTRODYNAMIC FORCES BETWEEN FULL-SIZE REACTORS}

These forces constitute the second effect of practical importance resulting from the mutual inductance between the parts of the winding of a given reactor, or between adjacent reactors. Increasing as the product of the currents in the two reactors (times the cosine of the time phase angle between the currents), these forces may become relatively very high ${ }^{32}$ during short circuit conditions. The use of model reactors for determining the translational forces between full-size reactors depends upon an ideally simple relation which applies to geometrically similar pairs of coils or other conducting structures, and which will now be developed.

The force $F_{x}$ in any direction $x$ between any two circuits traversed by currents $I_{1}$ and $I_{2}$ which are displaced in time phase by an angle $\theta$ is given by the well known formula

$$
F_{x}=I_{1} I_{2} \cos \theta \frac{d M}{d x}
$$

Referring to Figure 9, let the curve $M M^{\prime} N$ represent the mutual inductance between two coils as a function of the distance (in the direction $x$ ) between their axes. The ordinate $M X$, corresponding to the axial distance $O X$, is the maximum possible value of mutual inductance, and is for the case of coils in contact. As the distance between the axes increases the mutual inductance decreases as shown by the curve $M M^{\prime} N$, and for any given value of $I_{1} I_{2} \cos \theta$ the force in the direction $x$ will be proportional to the slope of this curve.

20 An exception is the diameter of the conductors; it is not necessary, in the determination of mutual inductance, to adhere at all closely to proportionality of conductor diameter, nor do the conductors need to be stranded or enameled as for the previous case where the skin-effect resistance ratio was an important item to be determined.

${ }_{30}$ This statement would not apply accurately to extreme cases where the two circuits are very closely coupled; for example, two coaxial disk or "pancake" coils separated by a relatively small axial distance. Such a case would hardly be even approximated, as far as the protective reactors under consideration are concerned.

${ }_{31}$ 'This second case is treated by H. B. Dwight; with a numerical example, in Trans. Am. Inst. Elec. Engrs., 38, pt. 2, pp. 1675-1681; 1919.

32 Kierstead and Stephens, Trans. Am. Inst. of Elec. Eng., 43, p. 909: 1924; report having observed forces as high as 33,000 pounds. They state that in the case of average feeder reactors the force is not over 10,000 pounds. 
Consider now a second pair of coils, geometrically similar to the first pair, similarly located with respect to each other, with the same number of turns in corresponding coils, but with all the dimensions reduced to $1 / p$ times those of the first pair. By relation (n), page 297, the mutual inductance of this second pair of coils for any relative position will be $1 / p$ times the mutual inductance of the larger pair for the corresponding position. The values of mutual inductance of the smaller pair, plotted to the same coordinates as the curve $M M^{\prime} N$ (fig. 9), will give the curve $m m^{\prime} n$, in which $m x$ is the maximum possible ordinate, for coils in contact, and corresponds to the ordinate $M X$ for the larger coils. Since the two curves have their corresponding abscissas differing only by the constant factor $1 / p$, and their corresponding ordinates also differing only by this same factor, the

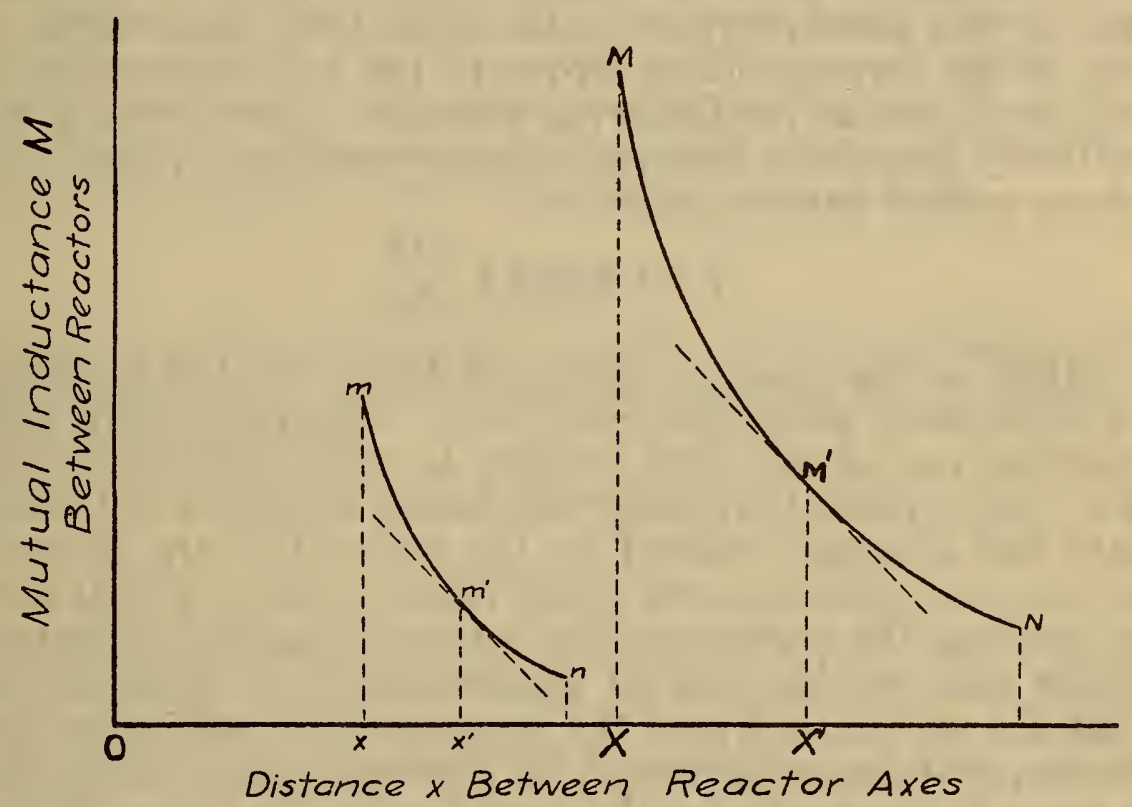

FIGURE 9.-Manner of variation of the mutual inductance of two pairs of reactors as a function of the distance between their parallel axes

The smaller curve $m n$ refers to a pair of coils geometrically similar to a larger pair to which the curve $M N$ applies. For geometrically similar configurations the value of $d M / d x$ is the same for each pair, as indicated by the tangents drawn as dotted lines.

tangent to $m m^{\prime} n$ at any point $m^{\prime}$ is equal to the tangent to the curve $M M^{\prime} N$ at the corresponding point $M^{\prime}$. But this tangent is equal to $d M / d x$, which (equation (12)) determines the force between a pair of coils for the given currents $I_{1}$ and $I_{2}$. This equality of forces is independent of the form of the coils and of the direction in which the force between them is resolved. Consequently, model reactors will develop the same force per ampere squared as the large reactors, for any given relative position, regardless of the scale to which the models are made. ${ }^{33}$

In general, even when immersed in oil the model reactors would not be able to carry currents equal to those which the full-size reactors must carry. On the assumption that the current density in the windings of the models is the same as in the full-size reactors, the models would carry $1 / p^{2}$ times as much current as the latter, and for the

33 Dwight, Formulas_for 1 Reactance Coils, Trans. A. I. E. E., 38, pt. 2, p. 1682; 1919, 
same time-phase angle between the currents the force would be $1 / p^{4}$ times that between the full-size reactors.

The force $F_{x}$ given by equation (12) is the average force, on the assumption that both reactors are rigidly secured to nonyielding supports, so that the relation of the natural frequency of oscillation (which depends on mass and resilience) to the electrical frequency does not introduce additional forces. ${ }^{34}$

\section{(f) ELECTRODYNAMIC TORQUE BETWEEN REACTORS}

In the preceding discussion the mutual electrodynamic forces tending to cause translation have been considered. If two reactors are so located that a torque can result from the interaction of their fields, the corresponding torque between two model reactors geometrically similar to them, to a scale of $1 / p$, with the same numbers of turns, for the same currents at the same time phase angle, will be only $1 / p$ of the corresponding torque of the full-size reactors. This fact may be shown in the following manner. The torque $T$ between two mutually inductive circuits carrying currents $I_{1}$ and $I_{2}$ with a time phase angle $\theta$ between them is

$$
T=I_{1} I_{2} \cos \theta \frac{d M}{d a}
$$

where $d M / d a$ is the rate of change of the mutual inductance with angle $a$ of rotation about the given axis. Comparing this case with the preceding one of the force tending to cause translation along an axis of $x$, it is evident that while the curves of Figure 9, having both ordinates and abscissas related by the factor $1 / p$, are geometrically similar and consequently have equal values of slope $d M / d x$ at corresponding points, the corresponding curves of mutual inductance for the torque case would have all the ordinates of $M$ reduced in the curve for the nodel to $1 / p$ of the corresponding values for the fullsize reactor, with no reduction of the abscissas (angles), which would be the same in the curve for the model as in the curve for the fullsize reactor; consequently the slope $d M / d a$ at each point on the curve for the model is $1 / p$ of the slope at the corresponding point of the curve for the full-size reactor.

\section{IRON-CORE AIR-GAP REACTORS}

\section{SCOPE OF THIS DISCUSSION}

The following discussion is intended to apply to reactors for frequencies of the ordinary values used for light and power circuits. It is not intended to apply without qualification to reactors for audio- and radio-frequencies, nor to reactors having an initial polarization produced by a direct current.

\section{REASON FOR THE USE OF AN AIR GAP}

The inductance of an iron-core reactor is a maximum when there is no air gap in the magnetic circuit, and the question naturally arises, why is an air gap generally used? The first and more obvious reason is that with a closed iron core the inductance varies greatly with the

"See Short-Circuit Forces on Reactor Supports I, by Doherty and Kierstead, Trans. Am. Inst. Elec] Engrs., 42, pp. 552-561; 1023. 
current because of the wide variation in the permeability of the core with change in flux density. Furthermore, the current will be relatively very small because of the very low reluctance; consequently a very small value of reactive volt amperes is obtained at the expense of the full amount of iron loss. Another important consideration in most cases is that the reactor should usually have the smallest possible ratio of total loss to reactive volt-amperes, ${ }^{35}$ or what is nearly the same thing, the smallest possible power factor, for a given bulk or weight or cost of the reactor. The following reasoning will show that this requires the presence of an air gap in the magnetic circuit.

The inductance of an iron-core air-gap reactor is

$$
L=4 \pi N^{2} / R
$$

where $N$ is the number of turns in the winding and $R$ is the reluctance of the entire magnetic circuit. The effective alternating current $I$ required to produce a cyclic magnetic flux in the gap with a prescribed maximum flux density in the iron core, and hence a given power loss in the iron per kilogram, will vary directly as $R$, that is

$$
I=k \Re
$$

The reactive power represented by the energy cyclically stored in the magnetic field in the gap and in the core and restored to the circuit by this current is

$$
\begin{aligned}
P_{r} & =L \omega I^{2}=L \omega k^{2} \mathbb{R}^{2} \\
& =4 \pi \omega k^{2} N^{2} \Re
\end{aligned}
$$

The reactive power will thus increase linearly ${ }^{36}$ as the length of the gap is increased, with iron losses remaining constant. The permissible upper limit to the length of the gap (for the condition of a constant value of iron losses) is set by the heating caused by the copper loss.

\section{CONDITION FOR THE DESIRABLE MINIMUM POWER FACTOR}

The purpose of a reactor being to introduce reactance into a circuit, and the unavoidable copper loss and iron loss being usually undesirable, it is of interest to determine the condition for which the power factor of the reactor will have its desirable minimum value. In the following it is again assumed that the magnetic flux density and, therefore, the total iron loss $P_{i}$ is kept constant as the total reluctance $R$ is increased by lengthening the gap. The current $I$ to maintain the chosen value of total flux will increase in proportion to $R$. The resistance of the winding being $r$, the total loss is the sum of the constant iron loss $P_{i}$ and the variable copper loss $I^{2} r$. The value of the reactive volt-amperes may be expressed by the relation

$$
P_{r}=a \Re
$$

\footnotetext{
35 This is equivalent to stating that the time-constant should be as high as possible. Unlike air-core inductance standards, iron-core reactors of the kinds under discussion are ordinarily designed for operation on a definite frequency, which makes the above terminology more convenient.

as This assumes that the cross section of the path of the magnetic flux in air does not change as the gap in made longer. Actually, the cross section increases. As an approximation, it has been suggested by Reed (Essentials of Transformer Practice, 2d ed., pp. 236-237) that each of the dimensions of the cross section of the air-gap flux, in the case of a rectangular iron core, be taken as equal to the corresponding dimension of the core increased by the length o ithe gap.
} 
where $a$ is a constant. It is more convenient to deal with $\cot \theta$, the ratio of total loss to reactive volt-amperes, than with the power factor $\cos \theta$, and the condition which makes $\cot \theta$ a minimum also makes $\cos \theta$ a minimum. Replacing the current $I$ by its equivalent $k \Omega$ by equation (15),

$$
\cot \theta=\left(P_{i}+k^{2} R^{2} r\right) / a R
$$

By differentiating this expression for $\cot \theta$ with respect to $Q$ it may be shown that for a minimum value of $\cot \theta$

$$
P_{i}=k^{2} R^{2} r=I^{2} r
$$

That is, the ratio of total loss to reactive volt-amperes, and, therefore, the power factor, will be a minimum when the copper loss equals the total iron loss. ${ }^{37}$

\section{SUGGESTED USE OF MODEL REACTORS AS A CHECK ON PRESENT METHODS OF DESIGN}

The inductance and other properties of an iron-core air-gap reactor may be predetermined by more or less approximate design procedures ${ }^{38}$ for the details of which the reader is referred to textbooks and original articles. It is the purpose of this section to show how a proposed design for such a reactor may be checked by the use of a small model. This would be done, in general, only when the full-size reactor is relatively large and expensive, for obviously if the reactor to be designed is of relatively small size (such as might be used, for example, as part of a frequency meter) it would be preferable to construct one of the actual design dimensions and to modify the design on the basis of its performance.

The performance of a proposed full-size iron-core air-gap reactor may be predetermined by tests made on a geometrically similar model reactor having all its dimensions $1 / n$ times the corresponding dimensions of the full-size reactor, including the diameter of the wire used in the winding. The number of turns in the coil of the model should be the same as the number proposed for the full-size reactor. However, in order that the iron loss per unit volume, at a given frequency and maximum induction, shall be the same in the model as in the fullsize reactor, the steel sheets used in the model should be of the same material and the same thickness as those to be used in the full-size reactor. These conditions being complied with, and the model being tested with a current $1 / n$ times the rated current to be carried by the winding of the full-size reactor, at the same frequency, the following relations will hold:

(o) The reactance of the full-size reactor will be $n$ times that of the model.

$(p)$ The reactive volt-amperes of the full-size reactor will be $n^{3}$ times the corresponding value for the model.

$(q)$ The iron losses in the full-size reactor will be $n^{3}$ times those in the model.

\footnotetext{
${ }^{37}$ Compare this with the similar relations for transformers; Reed, Essentials of Transformer Practice, $2 d$ ed., pp. $60,113$.

38 Reed, Essentials of Transformer Practice, pp. 146-148; Pender 8 S Handbook for Electrical Engineers, 2d ed., p. 1332; Standard Handbook for Electrical Engineers, 5th ed., p. 456; Edgcumbe, Industrial Electrical Measuring Instruments, 2d ed., p. 77; Drysdale and Jolley, Electrical Measuring Instruments, 1, p. 62; Wiggins, Elec. Jour., 24, pp. 20-22, 1927; Emde, Elektrot. und Maschinenbau, 48, pp. 521-530; 1930.
} 
( $r$ ) The copper loss in the full-size reactor, when rated current flows, will be $n$ times the copper loss in the model.

It may be that the use on the model of a winding having the same number of turns as in the proposed full-size reactor will result in a value of reactance in the model which is inconveniently low for measurement. To take care of this difficulty, the model may be wound with $p$ times the number of turns to be used in the full-size reactor. The resulting value of reactance of the model must in this case be multiplied by $n / p^{2}$ to get the reactance of the full-size reactor. Similarly, if the cross-sectional area of the wire used in winding the model is $1 / p n^{2}$ times that of the wire to be used on the full-size reactor, the resistance of the winding of the model must be multiplied by $1 / p^{2} n$ to get the resistance of the full-size winding.

The statement made above concerning the copper loss of the fullsize winding neglects the greater skin-effect resistance ratio in this winding. It is obviously impracticable to test the model at a higher frequency to take care of this matter, as can be done for a coil having no iron core, because of the uncertainty as to the effect of this higher frequency on the iron losses.

The fact that the copper loss of the full-size reactor is only $n$ times that of the model while the value of reactive volt-amperes is $n^{3}$ times as great means that the small size of the model makes it inefficient for the same reason that small transformers and small generators are inefficient. It implies also that to obtain the necessary data with the model it will be necessary to overload its winding considerably. This is erident from the fact that the wire used in winding the model, with only $1 / n^{2}$ times the cross section of the wire to be used on the full-size reactor, must carry $1 / n$ times the current of the latter. The resulting heating can be kept down, if necessary, by immersing the model in oil and by passing current through it only long enough to obtain readings. The container for the oil should be such as not to affect the performance of the model, either by altering the magnetic leakage flux or by providing a path for eddy currents.

It follows from relations $(o)$ to $(r)$, page 322 , that the power factor of the full-size reactor will be lower than that of the model, and can be determined from these relations. After experiments have been made on the model with various lengths of gap, values of reactance and of power factor of the full-size reactor for the various corresponding gap lengths can be computed and plotted as a function of gap length in order to find what gap length gives the required reactance, and what the corresponding value of power factor will be. These curves will have the general form shown in Figure 10. In this figure it will be noted that instead of power factor the ratio of watts loss (iron plus copper) to reactive volt-amperes has been used. The latter ratio is found by a simple division, while the power factor requires squaring these two quantities, extracting the square root of their sum, and dividing the watts loss by the result. Much labor will be saved by using $\cot \theta$, the ratio of watts to reactive volt-amperes, during the design process. It approximates more and more closely to the power factor $\cos \theta$ as the latter approaches zero, as may be seen from the following table, in which values of the ratio are rounded to the nearest unit in the third decimal place. 
TABLE 3

\begin{tabular}{|c|c||c|c|}
\hline $\begin{array}{c}\text { Power } \\
\text { factor, } \\
\text { cos } \theta\end{array}$ & $\begin{array}{c}\text { Ratio of } \\
\text { watts loss } \\
\text { to reactive } \\
\text { volt-am- } \\
\text { peres, cot } \theta\end{array}$ & $\begin{array}{c}\text { Power } \\
\text { factor, } \\
\text { cos } \theta\end{array}$ & $\begin{array}{c}\text { Ratio of } \\
\text { watts loss } \\
\text { to reactive } \\
\text { volt-am- } \\
\text { peres, cot } \theta\end{array}$ \\
\hline y. & & & \\
0.000 & 0.000 & 0.120 & 0.121 \\
.010 & .010 & .140 & .141 \\
.020 & .020 & .160 & .162 \\
.030 & .030 & .180 & .183 \\
.040 & .040 & .200 & .204 \\
.050 & .050 & .250 & .258 \\
.060 & .060 & .300 & .314 \\
.070 & .070 & .350 & .374 \\
.080 & .080 & .400 & .436 \\
.090 & .090 & .450 & .504 \\
.100 & .101 & .500 & .577 \\
\hline
\end{tabular}

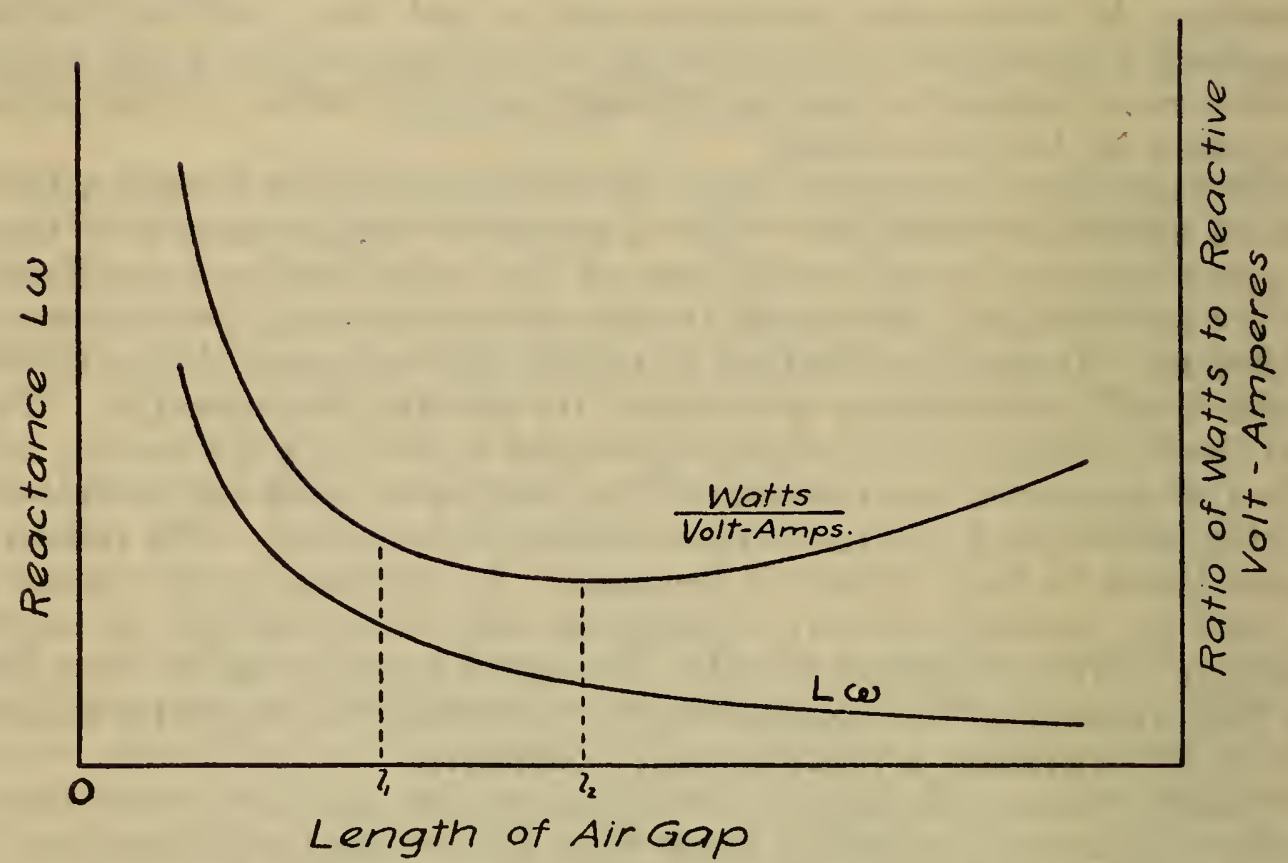

FIgURE 10.-Performance of an iron-core air-gap reactor as a function of the length of the air gap, with constant frequency, and with the current varied to maintain a constant value of maximum magnetic flux density in the core

From the curve $L \omega$ of Figure 10 the gap length which will give the required reactance can be ascertained, and also the corresponding value of the ratio of watts to reactive volt-amperes, which may be translated into power factor with the aid of Table 3. Referring to Figure 10, if the required value of reactance corresponds to the gap length $O l_{1}$, the ratio of watts to reactive volt-amperes will be greater than the minimum value possible with a reactor of these core dimensions, which minimum value is had when the gap length is $\mathrm{Ol}_{2}$. This latter gap length, however, corresponds to a value of reactance lower than the required value. Hence if the ratio of watts to reactive volt-amperes must be made lower the only remedy is to increase the dimensions of the proposed full-size reactor. A new set of curves is to be plotted from the data already observed on the model, using a somewhat larger dimension ratio $n_{2}$ in place of $n$. On the assumption that the rated current and the cross section of the conductor of the 
full-size reactor are to remain as originally planned, it is evident that the proposed larger full-size reactor will have a coil cross section greater than that originally proposed by the factor $\left(n_{2} / n\right)^{2}$, and that the number of turns will, therefore, be greater by this factor. The values of reactance of the proposed larger reactor, for any given relative gap lengths, will be $n_{2}^{5} / n^{4}$ times the corresponding values already observed for the model. ${ }^{39}$ Similarly, the reactive volt-amperes for the proposed larger reactor, with $\left(n_{2} / n\right)^{2}$ times the originally proposed number of turns, will be $n_{2}{ }^{5} / n^{2}$ times the reactive voltamperes of the model, for corresponding relative gap lengths; the iron loss will be $n_{2}{ }^{3}$ times that in the model, and the copper loss will be $n_{2}^{3} / n^{2}$ times that in the model, for corresponding relative gap lengths. These ratios may be derived from relations $(o)$ to $(r)$, inclusive. P. 322.

The new curves will resemble the set relating to the first proposed full-size reactor, but the required value of reactance (if $n_{2}$ has not been chosen too much greater than $n$ ) will be associated with a value of the ratio of watts to reactive volt-amperes lower than in the case of the first proposed reactor. If $n_{2}$ has been chosen too large, the required value of reactance may correspond to an unduly large relative length of air gap. This means a waste of material, at least, and possibly with it a needlessly large value of the ratio of watts to reactive volt-amperes. A smaller trial value of dimension ratio, intermediate between $n$ and $n_{2}$, should be tried, and the process repeated until a design is found in which the desired value of reactance occurs near the minimum value of the above ratio.

For very short relative lengths of gap the performance of the model reactor may approximate too closely (for some purposes) to that of an iron-core reactor without an air gap, in that the reactance will vary too much with the current. For such purposes, only those values of relative gap length should be considered for adoption for which the reactance of the model is sufficiently independent of the value of the current to satisfy the requirements of the particular application.

\section{SUGGESTED USE OF MODEL REACTORS AS AN INDEPENDENT BASIS OF DESIGN}

(a) UNCERTAINTY AS TO GAP RELUCTANCE, STRAY FLUX, ETC.

The uncertain elements in the methods of design now in use arise from the fact that the magnetic flux flows in part through leakage paths in a manner difficult to predetermine, and the flux across the air gap fringes out so that the cross section of the air-gap flux is greater than that of the iron core. When the gap is very short in comparison with the dimensions of the core perpendicular to the flux path, the reluctance of the gap will not differ greatly from that computed on the assumption of no leakage and no fringing of flux at the gap. As the relative length of the gap increases, the effects of leakage and fringing increase and it becomes increasingly difficult to predetermine the reluctance accurately. The use of models (or of a single model, the length of its gap being varied by steps) has

If the number of turns on the larger proposed reactor had been left the same as the number originally planned, its reactance would have been simply $n_{2}$ times the corresponding value for the model. Increasing the number of turns by the factor $\left(n_{2} / n\right)^{2}$ increases the reactance by the further factor $\left(n_{2} / n\right)^{4}$, that is, to $n g^{3} / n^{4}$ times that of the model. 
the advantage that the manner of leaking of the flux and fringing at the gap will be the same in the model as in any larger reactor which is geometrically similar in all dimensions, ${ }^{40}$ including gap length, provided the steel is worked at the same frequency and the same maximum value of induction. It is therefore suggested that the designer may begin by experiments on a model of suitable form, tested at a suitable value of maximum induction, and from the results compute the dimensions of a full-size reactor to have the desired electrical properties. The following general procedure is suggested:

\section{(b) CHOICE OF FORM OF CORE AND LOCATION OF GAP}

Various forms of core and locations of gap are used, and few general rules can be given. For economy of manufacture form-wound coils should be used if possible. From the standpoint of reducing leakage it is best to have the gap near the axial center of the coil, but this is not so convenient in some respects as are other arrangements where the gap is visible and accessible for measurement. The reader is referred to text books ${ }^{41}$ in which -typical forms are shown and their advantages and disadvantages discussed.

\section{(c) CHOICE OF CORE MATERIAL AND MAXIMUM FLUX DENSITY}

As previously stated, the material for the core is ordinarily silicon steel sheets of the grade and thickness used in power and lighting transformers (about $0.35 \mathrm{~mm}=0.014$ inch), and the maximum value of induction is properly chosen at about the same value as used in such transformers for the given frequency.

\section{(d) EXPERIMENTS TO BE MADE WITH THE MODEL}

Two windings should be used-one of relatively fine wire which does not surround the air gap and the regular winding which may or may not do so. The fine-wire winding is intended for use as a test coil to indicate when the flux in the iron has its desired value. The voltage $E$ in volts induced in it when current flows in the regular winding is to be measured ${ }^{42}$ and from it and the number of turns $N$ in the test coil, the frequency $f$ and the net cross-sectional area $A_{c m}$ of the iron core in $\mathrm{cm}^{2}$, the maximum magnetic induction in the core, $B_{\max }$, in maxwells per $\mathrm{cm}^{2}$, should be found by using the ordinary transformer equation

$$
E=4.44 N f B_{\max } A_{\mathrm{cm}} \times 10^{-8}
$$

from which

$$
B_{\max }=\frac{10^{8} \mathrm{E}}{4.44 N f A_{c m}}
$$

Some American designers, while expressing $B_{\max }$ in maxwells per $\mathrm{cm}^{2}$, prefer to express the net cross-sectional area of the core in square

10 Except the thickness of the sheet steel, which, as previously suggested, should be the same in the model and in the full-size reactor.

41 Drysdale and Jolley, Electrical Measuring Instruments, Pt. I, p. 65; Keinath, Die Technik der elek trischen Messgerite, 3d ed., 1, pp. 467-470.

12 If an a. c. potentiometer is available to measure this voltage, no correction for the resistance of the test coil is necessary. If it is necessary to use an a. c. voltmeter to measure the voltage induced in the test coil the voltmeter should preferably have a relativoly high resistance. If $R$, is the resistance of the voltmeter and $R_{c}$ that of the test coil, the voltmeter reading should be multiplied by $\left(R_{v}+R_{c}\right) / R_{*}$ to obtain the induced voltage. 
inches, for which case the expression for maximum induction takes the form

$$
B_{\max }=\frac{3.49 \times 10^{6} E}{N f A_{\text {in }}}
$$

The current $I$ in the main winding of the model during this test consists of two components; the one with which the designer is concerned, which sends the flux through the magnetic circuit, and another which by transformation supplies the current to operate the voltmeter. If the model core is of relatively small dimensions, or if the voltmeter is of relatively low resistance, it is necessary to eliminate the component of $I$ which by transformation operates the voltmeter. This can be done as follows: Note the increase $\Delta I$ of the main current when a second voltmeter of the same type and practically equal resistance is put in parallel with the first voltmeter; then reduce the original reading $I$ by an amount $\Delta I$ to get an approximate value of the current in the main winding which will excite the model core to the desired magnetic flux density.

The above procedure is to be repeated with the length of the air gap increased by successive steps of relatively moderate amount. Each time the current $I$ is to be adjusted to give the desired magnetic flux density in the core, as shown by the voltmeter reading, and the net current $I-\Delta I$ is to be determined.

(e) WORKING UP THE RESULTS OF EXPERIMENTS WITH THE MODEL

The next step is to assume some value of $n$, and on this basis to compute the performance of a larger, geometrically similar reactor. The results having been plotted as in Figure 10, the designer can judge whether the assumed full-size reactor will have the desired properties, and, if not, whether the next value of $n$ to be tried should be larger or smaller than the first one.

\section{CONDITION FOR MINIMUM POWER FACTOR IN EACH OF A SERIES OF GEOMETRICALLY SIMILAR REACTORS}

In a paper ${ }^{43}$ on the calculation of iron-core reactors of high timeconstant, Emde gives computed data for six reactors which form an ascending series with all the dimensions (except the length of the air gap) in the ratios $1: 2: 4: 8: 16: 32$. The equivalent air-gap lengths, ${ }^{44}$ however, are in the ratios $1: 4: 16: 64: 256: 1024$; in other words, the reactor which is larger in all its other dimensions by the factor $n$ has an equivalent air-gap length which is greater by the factor $n^{2}$. This one deviation from geometrical similarity is necessary to obtain the desirable minimum power factor for every reactor in the series, with the same frequency and the same flux density in the iron. To demonstrate this fact, assume that a reactor is avajlable in which the equivalent air-gap length has the value which makes copper loss equal to iron loss for a given flux density and given frequency, and that a larger reactor is to be made of the same materials with all its dimensions $n$ times as great. For simplicity, assume a single conducting turn

43 F. Emde, Elektrotechnik und Maschinenbau, 48, pp. 521-530; 1930. This paper covers the subject in a very thorough manner, including calculation of dimensions, minimum total cost of materials, cooling surface, etc.

4 The equivalent length of air gap may be defined as the length of an air gap having the same cross section as the actual air gap and a reluctance equal to the total reluctance of the given magnetic circuit. 
around the core in each reactor. With the same density of current in the copper and the same magnetic flux density in the core the copper losses and the iron losses of the second reactor will each be $n^{3}$ times the corresponding quantities for the first reactor. As shown above (p. 322), equality of these two losses is necessary to obtain the minimum power factor; therefore, the current in the second reactor is definitely fixed as $n^{2}$ times that in the first reactor. It remains to determine what length of air gap in the second reactor is compatible with this required current.

The cross section of the magnetic circuit in the larger reactor is $n^{2}$ times that of the smaller reactor, and the condition of equal flux density implies that the total flux in the second reactor is $n^{2}$ times that in the first. The setting up of $n^{2}$ times the flux by $n^{2}$ times the current means that the total reluctance is the same in both reactors, and this in turn means that the larger reactor with $n^{2}$ times the area of flux path must have an equivalent air-gap length $n^{2}$ times that of the smaller reactor.

The relatively greater equivalent length of gap in the larger reactor, with the same value of magnetic energy density, makes the ratio of total magnetic energy to total losses $n$ times as great in the larger reactor. This is equivalent to saying that $\cot \theta$ for the second reactor (which is very nearly the same as the power factor $\cos \theta$ ) is $1 / n$ times the value of $\cot \theta$ for the smaller reactor. Emde's table of data for his computed series of reactors includes values of time-constant and of $\cot \theta$. The ratio of mean length of flux path in iron to the equivalent air-gap length for the series decreases as $1 / n$ from the value 546 in the smallest reactor to 17 in the largest. Emde points out that one would usually have to discard as useless the two reactors at the lower end of his series because the air gaps are so short in comparison with the length of the flux path in iron that the curvature of the magnetization line is too great. For small values of time constant it may therefore be advantageous to use an air-core reactor.

\section{ACKNOWLEDGMENT}

The writer is greatly indebted to Dr. Frederick W. Grover for his careful reading of the manuscript, for many constructive suggestions for its improvement, for checking the correctness of the similitude relations concerning reactors (pp. 296, 297, 322, and 323), and for the computation of the data given in Table 1.

Washington, May 12, 1931. 